\title{
Editoriales universitarias y mercado Tendencias de comercialización en feria
}

\author{
( Ivana Mihal \\ Consejo Nacional de Investigaciones Científicas y Técnicas- CONICET. Universidad Nacional de San Martín - UNSAM. Argentina \\ | ivana.mihal@gmail.com / https://orcid.org/oooo-0oo2-2314-8003
}

\begin{abstract}
Resumen
Este artículo indaga cómo se desenvuelven en el mercado editorial los sellos de universidades nacionales de gestión pública, tomando como eje de análisis la comercialización de libros a través de un stand colectivo de la Red de Editoriales de Universidades Nacionales (REUN) del Consejo Interuniversitario Nacional (CIN) en el marco de la Feria Internacional del Libro de Buenos Aires. El período abarcado es el que se desarrolla entre 2014-2019 inclusive. Para las editoriales este evento significa la posibilidad de encontrarse con un público masivo y concentrado en un tiempo breve. Participar en esta feria anual es una de las oportunidades que se les presenta para difundir y vender los títulos de sus catálogos, dado que la mayoría de ellas, no cuenta con librerías universitarias ni stands propios. Específicamente, se analiza cómo se posicionan entre ellas, cuáles son los libros constitutivos de sus catálogos que orientan las tendencias de compra de quiénes asisten a las ferias, a través de una mirada sobre las áreas y géneros, temas y la preponderancia que tienen en las elecciones de los públicos las coediciones y las traducciones.
\end{abstract}

\section{University publishers and market: fair marketing trends}

\begin{abstract}
This article investigates how the public management of the national universities seals operate in the publishing market, taking as an axis of analysis the marketing of books through a collective stand of the Red de Editoriales de Universidades Nacionales (REUN) of the Consejo Interuniversitario National (CIN) within the framework of the Buenos Aires International Book Fair. The period covered is 2014-2019. For publishers, this event means the possibility of meeting a massive and concentrated audience in a short time. Being part of this annual fair is an opportunity to disseminate and sell catalog titles, considering that, most of them do not have university bookstores or stands. Specifically, it analyzes how they position themselves among them, which are the books in the catalogs, how they guide the purchasing trends in the fairs, through areas and genres study, and considering the topics and preponderance that co-editions and translations have in the public choices.
\end{abstract}


1. Las formas de inscripción y funcionamiento de las Asambleas inciden en la dificultad que tiene la REUN para llevar su registro (Mihal, 2019a).

2. En 2020, como consecuencia de la pandemia COVID-19 no se llevó a cabo presencialmente este evento.

\section{Introducción}

La edición universitaria argentina está conformada por editoriales universitarias y editoriales académicas -independientes y comerciales que publican libros de autores y títulos ligados al mundo intelectual- que no se arraigan en las universidades. Los estudios teóricos (Thompson, 2005; Chartier, 2007) sobre las universitarias -university press- en países anglosajones refieren que están basadas en la edición de libros científicos principalmente. En Argentina la publicación es una de las tareas de las universidades que tratan, mediante la diversificación de las obras que editan, de responder a los intereses de públicos lectores (Weinberg [1972] 2020). Por ende la categoría editoriales universitarias necesita tener en cuenta no solo los abordajes teóricos sino también un conjunto de sentidos, prácticas y normativas cotidianas (Mihal, 2019a). En este sentido, la composición de catálogos para públicos diversos tanto como su inscripción en el sistema educativo constituye parte de su conceptualización.

La actualización de los sellos universitarios de gestión pública reconocidas por el Consejo Interuniversitario Nacional (CIN) se lleva a cabo en cada Asamblea que tiene la Red de Editoriales de Universidades Nacionales (REUN). El reconocimiento del CIN se circunscribe a una editorial por universidad, aunque hay algunas universidades que tienen más de una, o cuentan con áreas o centros de publicaciones que dependen de alguna facultad o unidad académica y no de la estructura de una editorial. Cabe consignar que cuando el CIN se crea en 1985 nucleaba solamente a las universidades nacionales, pero en 1995 se aprueba la Ley de Educación Superior $\mathrm{N}^{\circ}$ 24521, por medio de la cual se reconoce como parte del sistema educativo en universidades nacionales, institutos universitarios y universidades provinciales. Con la sanción de esta ley el CIN pasa a tener en cuenta la ampliación del sistema de educación superior y esto incide en la edición universitaria que, a su vez, pasa a estar conformada también por editoriales constituidas en universidades provinciales e institutos universitarios. Generalmente la REUN organiza dos encuentros anuales, excepto en 2019, por lo cual según la última Asamblea que fue la de septiembre de 2018, 48 editoriales estaban inscriptas en el CIN (Mihal, 2019a). Aunque en el relevamiento de la REUN-CIN en 2019, el cuestionario de obtención de información fue enviado a 52 editoriales (de las cuales una era provincial) y fue respondido por sólo 35 de ellas (Dujovne, 2019), con lo cual es difícil precisar el número exacto pero estas rondan entre 48 y $52^{1}$.

La finalidad de este artículo es explorar y examinar la comercialización de libros de las editoriales universitarias nucleadas en la REUN en el marco de la Feria Internacional del Libro de Buenos Aires en el transcurso de los últimos cinco años ${ }^{2}$. Como sostiene Gustavo Sorá "lectores, autores, editores, bibliotecarios, categorías sociales jerárquicas, cotidianamente separadas por el objeto libro, se mezclan y se aproximan en el frenesí de la feria" (2016: 20). En estos espacios, distintos públicos pueden conocer la producción de las editoriales, a partir de las novedades y de otros títulos constitutivos de los catálogos que se exponen en los stands. Esto abre una serie de interrogantes: ¿qué títulos y autores han sido vendidos con mayor predominancia por cada editorial?; ¿qué temas y áreas del conocimiento han sido de mayor interés en base a las ventas?; ¿cómo se integran dichos títulos y autores a los catálogos de las editoriales?; ¿cuál es el lugar que ocupan las traducciones y las coediciones en la comercialización en estos espacios? Estas cuestiones procuran contribuir a brindar un panorama de la participación de la edición universitaria en un evento masivo como lo es dicha feria a fin de comprender los movimientos de estos sellos en un espacio y tiempo acotado de comercialización, en un ámbito concreto en el que tienen lugar otros actores y sectores del mundo editorial. 
Considero necesario, en primer lugar, delinear ciertas precisiones respecto al recorte, los materiales y análisis de datos en que se basa este artículo, que implicaron distintos tipos de fuentes para recabar información sobre las editoriales. En segundo lugar, me detengo en especificar y analizar los principales tópicos surgidos en relación con su participación en la feria a partir de la definición de un período concreto, situado entre 2014 y 2019 inclusive. En tercer lugar, reconstruyo en cada editorial la composición de los libros comercializados a través de la identificación de títulos que fueron más comprados en cada sello, relevo autoría, colección, coediciones, traducción y subgéneros o áreas disciplinares.

\section{Cuestiones metodológicas}

El enfoque es cualitativo y el recorte está centrado en editoriales de universidades nacionales de gestión pública inscriptas en la REUN, en el período ya especificado. Esto significa que he discriminado en las fuentes utilizadas los institutos universitarios, universidades privadas y editoriales de instituciones del sector público, independiente y comercial, y solo he tomado en cuenta los sellos que participan de la REUN.

Para la construcción de datos he combinado distintas fuentes de información, de carácter primario y secundario: bases de datos, catálogos, sitios web de las editoriales y universidades; registros de ISBN; conversaciones informales y entrevistas con directoras y directores editoriales. Pero el grueso del trabajo se desarrolla a partir de las bases de información construidas por la Librería Universitaria Argentina (LUA), a partir del stand de la REUN-CIN. Estas bases fueron tres, correspondientes a los años 2014-2017, 2018 y 2019. Presentaban algunas imprecisiones de títulos, autorías y/o nombres de editoriales, por lo cual fue necesario reconstruir la información. Para ello revisé los registros de ISBN, los cuales, salvo algunas excepciones estaban incompletos, esto significa que muchas veces se ha cargado un libro sin especificar el sello coeditor de la obra o traducción de la misma.

Paralelamente a la información suministrada por el ISBN he ido chequeando y cotejando los catálogos. La descripción, ordenamiento y revisión de los catálogos (mayormente en soporte online) posibilita identificar si los libros consultados integran una colección o serie, tanto como comprender ciertos aspectos de la lógica de circulación de la producción editorial y en este último sentido, es posible observar a quiénes se apunta como público tanto como contextualizar los libros. Sin embargo, un problema no menor en su revisión ha sido que en reiteradas ocasiones es difícil identificar la producción editorial activa tanto como la descatalogada a través de los mismos. A este problema, se agregó otro vinculado con la desactualización de novedades de algunas editoriales tanto como la inexistencia de un catálogo disponible online.

La búsqueda de información, que pudiera salvar dichos problemas, por medio de internet implicó tres criterios: 1) las noticias que las universidades publican cuando no fue localizable un título por otras vías y que refieren principalmente a las presentaciones oficiales de libros en actos o ferias; 2) la lectura de la sinopsis de libros y, en última instancia, cuando ni por medio de la editorial ni de la universidad encontré un título recurrí a otros sitios de venta como los de comercialización online, los cuales publican las tapas de libros. Sin embargo, este último criterio fue muy poco utilizado; 3) a través de las conversaciones informales con directoras y directores editoriales he podido despejar algunas dudas surgidas a partir de la información incompleta del ISBN o de la falta de ubicación en una colección de un libro que estaba consignado en la base de datos de la LUA. 
3. Los otros desafíos eran los cambios en las prácticas de lectura en relación con el libro -reducción en los compradores de libros (remitiéndose al caso francés) y de adquisiciones por parte de las bibliotecas universitarias y por ende la reorientación de la edición universitaria a publicar libros demasiado especializados en ciencias sociales y humanas de carácter monográfico -resultados de tesis y otros documentos- (retomando el caso norteamericano y de otros países europeos); y por último, la edición de libros electrónicos y el trabajo editorial que implican que los distingue de otras publicaciones electrónicas.

4. En 2015 tras la asunción de nuevas autoridades en el gobierno nacional, el Ministerio pasó a integrarse con el área de Deportes, pasando a ser el Ministerio de Educación y Deportes de la Nación. En 2017 se separa Deportes. En 2018 se incorporan en un mismo ministerio cuatro áreas, Educación, Cultura, Ciencia y Tecnología. En diciembre de 2019 se divide y quedó como Ministerio de Educación.

5. Las compras de libros por parte del Estado disminuyeron en los últimos años, conjuntamente con la suspensión a la restricción de las importaciones de libros; la devaluación del peso argentino; el aumento de los costos e insumos de impresión cotizados en dólares y la caída en los consumos culturales.

6. Como ya mencioné no doy cuenta en este artículo las ganancias totales de esas ventas.

7. Como señalan los informes de la Cámara Argentina del Libro en esos años, disponibles en https://www. camaradellibro.com.ar/index.php/ panorama-editorial/estadisticas

8. El proceso iniciado con el retiro de 2016 de la SPU del financiamiento de la LUA terminó con su traslado a una librería comercial con la que compartía edificio, posteriormente a un depósito y finalmente a una librería en el $\mathrm{CIN}$, aunque lejos de tener las

dimensiones y el alcance que tuvo cuando se creó en 2013. A esto se sumó la crisis de las propias universidades y los recortes de subsidios, de becas, entre otros.
Para el análisis de bases tomé en consideración además de la selección de sellos de universidades nacionales: 1) los ejemplares más vendidos de un título: fueron tenidos en cuenta tanto los comercializados a través de cada editorial como de otros proveedores, dado que no interesaba analizar los ingresos gananciales de los sellos sino la relevancia de los títulos que componen sus fondos editoriales; 2) si el título más vendido fue una coedición o una traducción este tienen valor en tanto tal, por lo cual ante la detección de una obra traducida o coeditada la discriminé y consideré el siguiente título más vendido. Respecto de las traducciones, la identificación en el ISBN de las traductoras y los traductores es reciente por lo cual en aquellos libros que son el resultado de reimpresiones de muchos años no ha sido posible visualizar la autoría de la traducción. En cuanto a las coediciones, relevé los casos más significativos en términos de ventas; 3 ) en algunos pocos casos coexisten más de uno de estos criterios de clasificación, cuando una obra por ejemplo es publicada en coedición y es resultado de una traducción; 4) si la obra es producto de una compilación o dirección, como parte de una autoría colectiva en la cual cada autora y autor escribe una parte o sección, o es de autoría única, también fue deslindado; y 5) la ubicación en el campo académico en dos grandes áreas, ciencias sociales y humanas, tratando de especificar lo máximo posible las subáreas disciplinares. Sin embargo, un mismo libro puede ser clasificado de diversos modos: por ejemplo, los que se centran en la Reforma Universitaria pueden ser comprendidos como parte de la Historia de la Educación Argentina, tanto como ser interpretados como Educación Superior. La clasificación de obras, por ejemplo, en tema y especialidad supone arbitrariedades y contradicciones aun cuando la finalidad es descriptiva (Bonacci, 2012). A sabiendas de dichas arbitrariedades, fue preciso identificar cómo estaban descriptos en el ISBN, a veces cotejar cómo se los definía en el catálogo (lo cual no siempre se corresponde con el ISBN), y en otras ocasiones remitirme a la sinopsis de los libros.

\section{Las editoriales universitarias y la Feria}

Hace algunos años, Chartier en una entrevista con los editores de EDUVIM y de Ediciones UNGS planteaba que uno de los tres desafíos que atraviesan la edición universitaria es la publicación de libros sobre temas en boga atractivos al "gran público"” (Chartier, 2014). El encuentro con ese gran público es el que se desarrolla en el marco de esta feria. Incluso, parte de la paulatina visibilidad que fueron adquiriendo en el mercado los sellos se relaciona con el crecimiento en presencia y cantidad de títulos. Costa y de Sagastizábal (2016) sostienen que la REUN de 2005 a 2015 -con el apoyo de la Secretaría de Políticas Universitarias (SPU) del Ministerio de Educación de la Nación ${ }^{4-}$, tuvo una curva ascendente que comenzó en 2005 con un stand de 40 metros cuadrados, libros de 22 editoriales y 756 títulos, llegando a 2015 con un stand de 102 metros cuadrados' 36 editoriales y 1.290 títulos. Asimismo, destacan que 2015 fue un año exitoso en términos de la venta de más de 1500 ejemplares, como por las editoriales que lo encabezaron -Ediciones UNGS, EUDEBA, UNQ editorial, EDIUNC y EDUVIM-, las que se destacan por su gestión, por el diseño, por sus títulos, autores y por las traducciones que integran sus catálogos (Costa y de Sagastizábal, 2016). No obstante, en los últimos años varios factores contribuyeron ${ }^{5}$ al descenso en la cantidad de ejemplares vendidos ${ }^{6}$, algunos intrínsecos al sector editorial en general ${ }^{7}$ y otros a la edición universitaria ${ }^{8}$. 
Los sellos participantes que han realizado ventas de libros en el stand del CINREUN coordinado por la Librería Universitaria Argentina (LUA) -encargada esta última de la gestión de su comercialización- han sido relativamente estables en el transcurso del tiempo (Cuadros 1, 2 y 3). Varias de las editoriales aun cuando fueron creadas hace muchos años estuvieron inactivas y terminaron refundándose, en cambio, otras son de reciente surgimiento como Libros UNA que se origina en 2015, la de UNDEF en 2017 y las de las Universidades Nacionales de Hurlingam y de Rafaela en 2018. El relevamiento de la REUN-CIN en 2019 muestra grandes saltos en su generación, en 1958 se crea EUDEBA, en 1987 EDULP, y entre 1987 y 1999 se generan otras 10, sin embargo, el período más prolífico es el desarrollado entre 2003 y 2018 con la constitución de otros 25 sellos (Dujovne, 2019).

En este evento, como en otras ferias del libro, la localización espacial de los stands permite observar jerarquías y clasificaciones en relación con el mercado del libro (Sorá, 2002) que inciden en la comercialización. El stand de la REUNCIN en el 2018 estuvo ubicado en el pabellón Ocre del predio, en donde suelen estar localizados los stands institucionales de las provincias. Esto actuó como un factor de disminución de las ventas en ese año, según el entonces coordinador ejecutivo de la REUN: "nuestro lugar es el pabellón azul, ese es nuestro lugar! Este año estuvimos en el azul cerca de Waldhuter, de la UNQ, y cercanos a EUDEBA" (comunicación personal propia, 6 de septiembre de 2019). La librería Waldhuter, los stands de Ediciones UNGS, Ediciones UNQ, EDUNTREF, por ejemplo, son algunos de los sellos que estuvieron ubicados en 2019 en el pabellón azul, próximo también al pabellón verde en el cual se situaban EUDEBA, Ediciones UNL, Siglo XXI, entre otras vinculadas con la edición universitaria y académica. En la feria realizan adquisiciones tanto públicos que compran un ejemplar como distribuidores e instituciones que adquieren libros en cantidad. Con respecto a las instituciones, la Comisión Nacional Protectora de Bibliotecas Populares a través del Programa Libro\% otorga un subsidio a las bibliotecas populares adscriptas al organismo para la compra de libros con descuentos en ese marco. Teniendo en cuenta esta diversidad de públicos es que resulta estratégico el lugar que se ocupa dentro del predio. La ubicación de los stands en las ferias, como plantea Szpilbarg (2017) posibilita observar no solo como los grandes grupos editoriales logran obtener las mejores posiciones sino también cómo el asociativismo o la reunión de varios sellos facilita la participación de editoriales que no podrían solventar y sostener un stand individual. En 2019 Ediciones UNGS, UNQ Ediciones y EDUNTREF participaron del stand de la REUN-CIN pero también tuvieron stands propios.

Otras editoriales compartieron además de este último, sus producciones en stand colectivos dedicados a la edición universitaria como el de EUDEBA al que se suma Ediciones UNL y EDUNER. EDUNT integra el stand también con la Provincia de Tucumán y en 2018 y 2019 un equipo de la propia editorial organizó y estuvo a cargo de actividades más en dicho espacio que en el de la REUN, lo cual según su directora editorial es fundamental porque realizan mayor cantidad de ventas en el provincial (entrevista propia, 21 de mayo de 2019). 
Cuadro 1.

Editoriales participantes de la comercialización en feria (2014-2017)

\begin{tabular}{|c|c|c|}
\hline Universidades & Editoriales 2014-2017 & $\begin{array}{c}\% \\
\text { ventas }\end{array}$ \\
\hline Universidad Nacional de General Sarmiento & Ediciones UNGS & 9,73 \\
\hline Universidad Nacional de Villa María & EDUVIM & 7,75 \\
\hline Universidad de Buenos Aires & EUDEBA & 5,61 \\
\hline Universidad Nacional de Quilmes & UNQ Editorial & 4,98 \\
\hline Universidad Nacional de San Martín & UNSAM Edita & 4,83 \\
\hline Universidad Nacional de Cuyo & EDIUNC & 4,77 \\
\hline Universidad Nacional de La Plata & EDULP & 4,60 \\
\hline Universidad Nacional de Entre Ríos & EDUNER & 4,41 \\
\hline Universidad Nacional de Mar del Plata & EUDEM & 4,19 \\
\hline Universidad Nacional de Río Cuarto & UNIRIO Editora & 4,16 \\
\hline Universidad Nacional del Litoral & Ediciones UNL & 3,90 \\
\hline Universidad Nacional del Sur & EDIUNS & 3,58 \\
\hline Universidad Nacional de Moreno & UNM EDITORA & 3,51 \\
\hline Universidad Nacional de Rosario & UNR Editora & 3,09 \\
\hline Universidad Nacional de Córdoba & Editorial de la UNC & 2,97 \\
\hline Universidad Pedagógica Nacional & UNIPE Editorial Universitaria & 2,72 \\
\hline Universidad Nacional de Lanús & EDUNLA Cooperativa & 2,48 \\
\hline Universidad Nacional Arturo Jauretche & UNAJ & 2,44 \\
\hline Universidad Nacional del Centro & Editorial UNICEN & 2,15 \\
\hline Universidad Nacional de La Pampa & EDUNLPAM & 1,94 \\
\hline Universidad Nacional de Misiones & EDUNAM & 1,70 \\
\hline Universidad Nacional del Noroeste & CEDI-UNNOBA & 1,25 \\
\hline Universidad Nacional de San Luis & N.E.U. (Nueva Editorial Universitaria) & 1,22 \\
\hline Universidad Nacional de Santiago del Estero & EDUNSE & 1,19 \\
\hline Universidad Nacional de Avellaneda & UNDAV Ediciones & 1,17 \\
\hline Universidad Nacional de Luján & EDUNLU & 1,12 \\
\hline Universidad Nacional de Salta & EUNSA & 1,07 \\
\hline Universidad Nacional de Río Negro & Editorial UNRN & 1,04 \\
\hline Universidad Nacional de Jujuy & EDIUNJU & 0,97 \\
\hline Universidad Nacional de Catamarca & E.C.U. (Editorial Científica Universitaria) & 0,94 \\
\hline Universidad Nacional de Tucumán & EDUNT & 0,90 \\
\hline Universidad Tecnológica Nacional & EDUTECNE & 0,86 \\
\hline Universidad Nacional de Tres de Febrero & EDUNTREF & 0,66 \\
\hline Universidad Nacional de San Juan & E.F.U. (Editorial Fundación Universitaria) & 0,57 \\
\hline Universidad Nacional de La Matanza & UNLaM Editorial & 0,37 \\
\hline $\begin{array}{l}\text { Universidad Nacional de Tierra del Fuego, Antártida } \\
\text { e Islas del Atlántico Sur }\end{array}$ & Ediciones UNTDF & 0,35 \\
\hline Universidad Nacional del Nordeste & EUDENE & 0,24 \\
\hline Universidad Nacional de la Patagonia San Juan Bosco & EDUPA & 0,10 \\
\hline Universidad Nacional del Comahue & EDUCO & 0,09 \\
\hline Universidad Nacional de la Defensa & UNDEF Libros & 0,07 \\
\hline Universidad Autónoma de Entre Ríos & Editorial UADER & 0,06 \\
\hline Universidad Nacional de las Artes & Libros UNA & 0,05 \\
\hline
\end{tabular}




\begin{tabular}{|c|c|c|}
\hline Universidades & Editoriales 2018 & $\begin{array}{c}\% \\
\text { de ventas }\end{array}$ \\
\hline Universidad Nacional de Villa María & EDUVIM & 12,38 \\
\hline Universidad Nacional de General Sarmiento & Ediciones UNGS & 10,03 \\
\hline Universidad Nacional de San Martín & UNSAM Edita & 7,79 \\
\hline Universidad Nacional de Entre Ríos & EDUNER & 5,61 \\
\hline Universidad Nacional de La Plata & EDULP & 5,05 \\
\hline Universidad Nacional de Córdoba & Editorial de la UNC & 3,99 \\
\hline Universidad Nacional de Río Cuarto & UNIRIO Editora & 3,79 \\
\hline Universidad Pedagógica Nacional & UNIPE Editorial Universitaria & 3,79 \\
\hline Universidad Nacional del Litoral & Ediciones UNL & 3,66 \\
\hline Universidad Nacional de Mar del Plata & EUDEM & 3,36 \\
\hline Universidad Nacional de Cuyo & EDIUNC & 3,33 \\
\hline Universidad de Buenos Aires & EUDEBA & 2,87 \\
\hline Universidad Nacional de Río Negro & Editorial UNRN & 2,70 \\
\hline Universidad Nacional del Sur & EDIUNS & 2,37 \\
\hline Universidad Nacional de San Luis & $\begin{array}{l}\text { N.E.U. (Nueva Editorial Univer- } \\
\text { sitaria) }\end{array}$ & 2,31 \\
\hline Universidad Nacional del Noroeste & CEDI UNNOBA & 2,24 \\
\hline Universidad Nacional de Rosario & UNR Editora & 2,24 \\
\hline Universidad Nacional de La Pampa & EDUNLPAM & 2,14 \\
\hline Universidad Nacional de Avellaneda & UNDAV Ediciones & 2,11 \\
\hline Universidad Nacional de Misiones & EDUNAM & 2,08 \\
\hline Universidad Nacional de Tres de Febrero & EDUNTREF & 2,04 \\
\hline Universidad Nacional de Moreno & UNM EDITORA & 1,84 \\
\hline Universidad Nacional de Luján & EDUNLU & 1,75 \\
\hline Universidad Nacional de José C. Paz & EDUNPAZ & 1,45 \\
\hline Universidad Nacional del Nordeste & EUDENE & 1,15 \\
\hline $\begin{array}{l}\text { Universidad Nacional de Tierra del Fuego, } \\
\text { Antártida e Islas del Atlántico Sur }\end{array}$ & Ediciones UNTDF & 1,05 \\
\hline Universidad Nacional de Santiago del Estero & EDUNSE & 1,02 \\
\hline Universidad Nacional del Centro & Editorial UNICEN & 1,02 \\
\hline Universidad Nacional de Lanús & EDUNLA Cooperativa & 0,89 \\
\hline Universidad Nacional de las Artes & Libros UNA & 0,56 \\
\hline Universidad Nacional de Catamarca & $\begin{array}{l}\text { E.C.U. (Editorial Científica } \\
\text { Universitaria) }\end{array}$ & 0,52 \\
\hline Universidad Nacional Arturo Jauretche & UNAJ & 0,52 \\
\hline Universidad Nacional de Tucumán & EDUNT & 0,46 \\
\hline Universidad Tecnológica Nacional & EDUTECNE & 0,36 \\
\hline Universidad Nacional del Comahue & EDUCO & 0,33 \\
\hline Universidad Nacional de Jujuy & EDIUNJU & 0,29 \\
\hline Universidad Autónoma de Entre Ríos & Editorial UADER & 0,23 \\
\hline Universidad Nacional de La Matanza & UNLaM & 0,19 \\
\hline Universidad de la Defensa Nacional & UNDEF Libros & 0,16 \\
\hline Universidad Nacional de Lomas de Zamora & Editorial UNLZ & 0,09 \\
\hline Universidad Nacional de Salta & EUNSA & 0,03 \\
\hline
\end{tabular}

Cuadro 2. Editoriales participantes de la comercialización en feria (2018) 
Cuadro 3. Editoriales participantes de la comercialización en feria (2019)

\begin{tabular}{|c|c|c|}
\hline Universidades & Editoriales 2019 & $\begin{array}{l}\% \\
\text { de ventas }\end{array}$ \\
\hline Universidad Nacional de General Sarmiento & Ediciones UNGS & 8,64 \\
\hline Universidad Nacional de Villa María & EDUVIM & 7,29 \\
\hline Universidad Nacional de La Plata & EDULP & 6,54 \\
\hline Universidad Pedagógica Nacional & UNIPE: Editorial Universitaria & 6,04 \\
\hline Universidad Nacional de San Martín & UNSAM Edita & 5,83 \\
\hline Universidad Nacional de Córdoba & UNC & 4,97 \\
\hline Universidad Nacional de Mar del Plata & EUDEM & 4,87 \\
\hline Universidad Nacional de Luján & EDUNLU & 4,48 \\
\hline Universidad Nacional de Río Cuarto & UNIRIO Editora & 4,19 \\
\hline Universidad Nacional de Moreno & UNM EDITORA & 3,69 \\
\hline Universidad Nacional de Tres de Febrero & EDUNTREF & 3,23 \\
\hline Universidad Nacional de Río Negro & Editorial UNRN & 3,20 \\
\hline Universidad Nacional de Cuyo & EDIUNC & 3,09 \\
\hline Universidad Nacional de José C. Paz & EDUNPAZ & 2,66 \\
\hline Universidad Nacional de Quilmes & UNQEditorial & 2,66 \\
\hline Universidad Nacional de Entre Ríos & EDUNER & 2,45 \\
\hline Universidad Nacional de Santiago del Estero & EDUNSE & 2,41 \\
\hline $\begin{array}{l}\text { Universidad Nacional de Tierra del Fuego, Antár- } \\
\text { tida e Islas del Atlántico Sur }\end{array}$ & Ediciones UNTDF & 2,27 \\
\hline Universidad Nacional del Litoral & Ediciones UNL & 1,95 \\
\hline Universidad Nacional de Lanús & EDUNLA Cooperativa & 1,95 \\
\hline Universidad Nacional de Rosario & UNR Editora & 1,95 \\
\hline Universidad Nacional de Jujuy & EDIUNJU & 1,63 \\
\hline Universidad Nacional de Luján & EDUNLU & 1,38 \\
\hline Universidad Nacional de las Artes & Libros UNA & 1,38 \\
\hline Universidad Nacional del Centro & Editorial UNICEN & 1,38 \\
\hline Universidad Nacional de La Pampa & EDUNLPAM & 1,24 \\
\hline Universidad Nacional de Avellaneda & UNDAV Ediciones & 1,13 \\
\hline Universidad Nacional de Misiones & EDUNAM & 1,13 \\
\hline Universidad Nacional Arturo Jauretche & UNAJ & 0,99 \\
\hline Universidad de Buenos Aires & EUDEBA & 0,78 \\
\hline Universidad Nacional del Noroeste & CEDi-UNNOBA & 0,78 \\
\hline Universidad Nacional de San Luis & NEU & 0,60 \\
\hline Universidad Nacional del Sur & EDIUNS & 0,56 \\
\hline Universidad Nacional de Tucumán & EDUNT & 0,49 \\
\hline Universidad de la Defensa Nacional & UNDEF Libros & 0,49 \\
\hline Universidad Nacional de Rafaela & Ediciones UNRAF & 0,46 \\
\hline Universidad Nacional del Nordeste & EUDENE & 0,35 \\
\hline Universidad Nacional de Hurlingam & UNAHUR & 0,24 \\
\hline Universidad Autónoma de Entre Ríos & Editorial UADER & 0,17 \\
\hline Universidad Nacional de Catamarca & UNdeC & 0,14 \\
\hline Universidad Nacional de la Patagonia Austral & UNPAedita & 0,10 \\
\hline
\end{tabular}




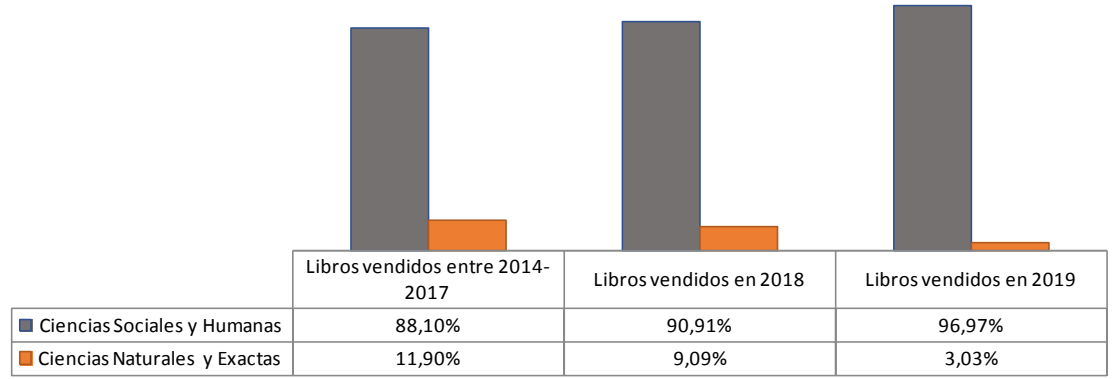

Fuente: elaboración propia
Gráfico 1. Porcentaje de libros vendidos (2014-2019)

Enfocando la mirada en los resultados de la comercialización en el período indagado -sin tener en cuenta las coediciones-, esta ha registrado entre 2014 y 2017 inclusive un total de 11063 ejemplares vendidos, en 2018 de 3028 y en 2019 de 2812 . Si se observa el porcentaje de cada editorial (Cuadros 1, 2 y 3 ), es posible advertir la preponderancia en ventas de un grupo de entre 10 y 12 sellos aproximadamente por sobre otros, que se mantienen en el liderazgo en los distintos años.

Geográficamente lideran las universidades ubicadas en la zona centro del país, con los sellos de Ediciones UNGS, UNQ Editorial UNSAM Edita, EDULP, EUDEM, EUDEBA, EDIUNS en los primeros lugares. A éstas les siguen las editoriales ubicadas en las provincias de Córdoba con EDUVIM y UNIRÍO; de Entre Ríos con EDUNER; y de Mendoza con UNCUYO. Esta representación tiende a reiterarse en 2018 y en 2019 con algunas variaciones. En el 2018 con la presencia de Santa Fe con Ediciones UNL y la incorporación de otra universidad de Córdoba, Editorial de la UNC y en la CABA con el ascenso sostenido del sello de UNIPE que, creado en 2015, ya en solo tres años se posiciona entre los de mayor venta, y continúa con dicho crecimiento en 2019, y el descenso de EUDEBA. Asimismo, se observa el ascenso progresivo en ventas en otras como EDUNLU, Libros UNA, Ediciones UNTDF y de la Editorial de la Universidad Nacional de Río Negro.

\section{Composición de las ventas según representación editorial}

En la introducción planteaba la necesidad de visualizar cómo se integran títulos y autores al catálogo de las editoriales, a partir de las elecciones que realizan los asistentes a la feria. Esto permite observar las prácticas editoriales y las colaboraciones y competencias al interior de los campos especializados en las que se segmentan y dar cuenta de cómo se ordenan y jerarquizan discursos a través de catálogos, colecciones y series (Soares Rodriguez y Souza Muñiz Jr., 2018). En primer lugar, es preciso destacar que la mayor comercialización de libros desde 2014 a 2019 inclusive corresponde al gran género Ciencias Sociales y Humanas, y en mucha menor proporción al área de Ciencias Naturales y Exactas (Gráfico 1). En segundo lugar, las colecciones organizan en gran medida el catálogo de la mayoría de las editoriales, y en algunos casos los catálogos cuentan con menos cantidad de colecciones y más cantidad de series como en Ediciones UNL.

En las Ciencias Sociales y Humanas predominan en las ventas, en el período 20142017 (Gráfico 2), los libros que tratan principalmente cuestiones ligadas a Educación -EDUNLU, Editorial UNICEN, UNLAM, y E.C.U.- Seguidos por los subgéneros Política -EUDEM, UNDAV Ediciones, UNDEF Libros y EDUCO-; Género(s) Ediciones UNGS, EDUVIM, EDUNER y EDUNAM-; Historia, basada en el caso 


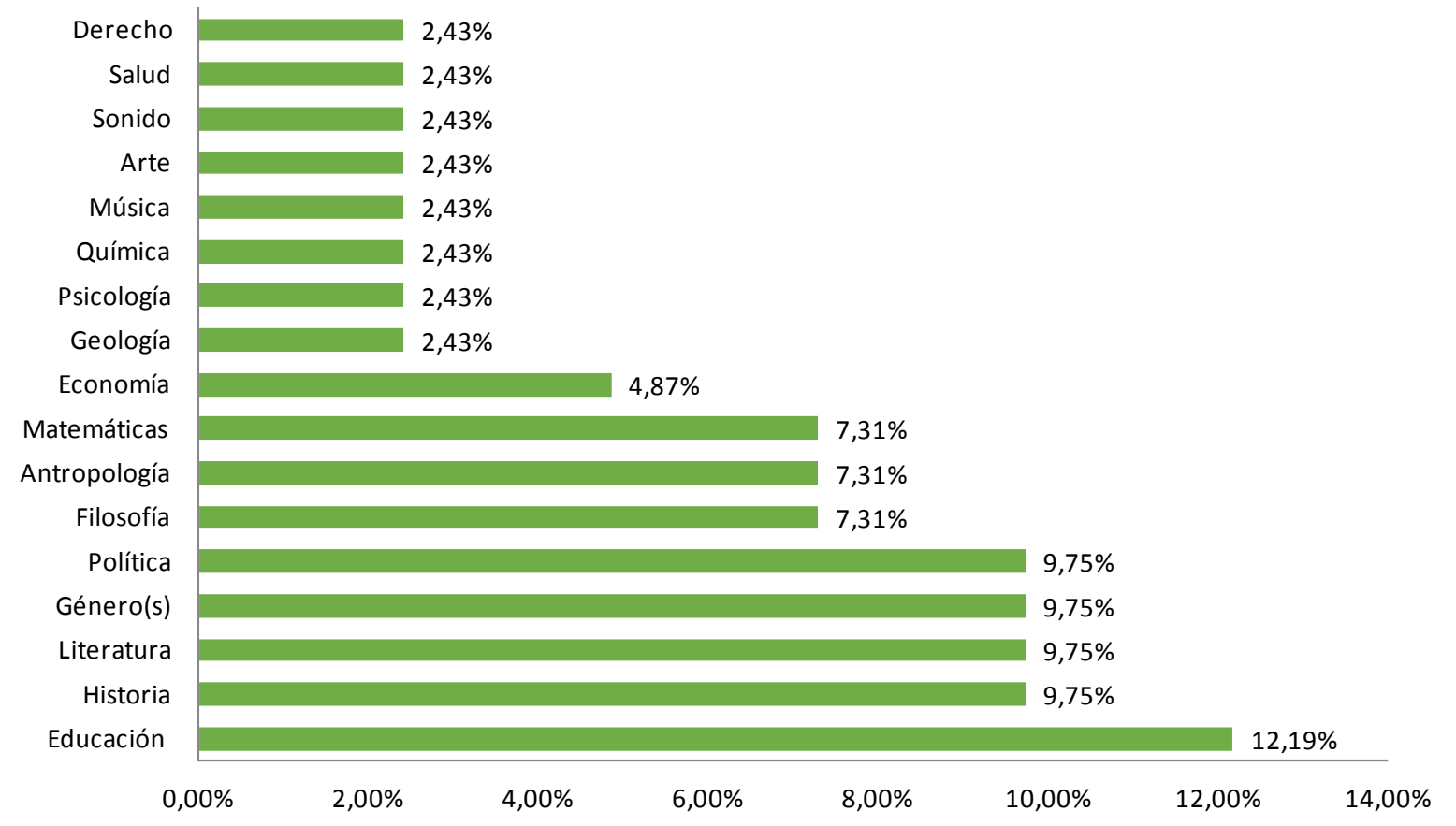

\section{Gráfico 2. Subgéneros más vendidos en el período 2014-2017}

Fuente: elaboración propia a partir de la información relevada Feria 2014-2017 por la LUA

argentino -UNQ Editorial, EDUNLA, CEDI-UNNOBA, Editorial de la UNC-; y Literatura-UNIPE Editorial Universitaria, EDULP, Editorial de la UNC, Ediciones UNTDF-. Antropología-EDUNSE, EUDENE y Editorial UNRN-.

Respecto a los títulos y, por consiguiente, a los subgéneros que han alcanzado mayor comercialización en cada sello (Cuadro 4), cabe consignar algunos aspectos. Primero, que el Nunca Más fue el título que posicionó a EUDEBA en quinto lugar en cantidad de ejemplares vendidos y es quizás el bestseller más importante editado en el marco de una editorial universitaria. Según de Sagastizábal (2008), este libro no sólo constituyó uno de los mayores éxitos de esta editorial, sino que inauguró una colección centrada en Derechos Humanos como parte de su plan editorial. Segundo, los títulos orientados al trabajo aúlico también registran fuertes ventas como en el caso de EDIUNC, EDUNLU, Editorial UNICEN, Ediciones UNL, EDULPAM, EDIUNJU y EDUNT aunque de temáticas variadas. Tercero, algunos sellos aunque no reportan un título sobresaliente de su catálogo en las ventas, tienen más de un título coexistiendo como el más vendido como en el caso de la Editorial de la UNC y de EDIUNJU, aunque en este último caso ambos libros forman parte de la misma colección. 
Cuadro 4. Principales títulos vendidos en el período 2014-2017

\begin{tabular}{|c|c|c|c|c|}
\hline Editorial & Título & Autoría & Clasificación & Cant. \\
\hline $\begin{array}{l}\text { Ediciones } \\
\text { UNGS }\end{array}$ & Yo nena, yo princesa & Gabriela Mansilla & $\begin{array}{l}\text { Colección Interven- } \\
\text { ciones }\end{array}$ & 98 \\
\hline EDIUNC & Código Civil y Comercial de la Nación & & Colección Varios & 78 \\
\hline EDUVIM & $\begin{array}{l}\text { La revolución de las mujeres. No era solo } \\
\text { una píldora }\end{array}$ & Luciana Peker & $\begin{array}{l}\text { Col. Proyectos Espe- } \\
\text { ciales }\end{array}$ & 50 \\
\hline UNM Editora & $\begin{array}{l}\text { Recorridos y actividades para la práctica } \\
\text { de la lectura y la escritura en la educación } \\
\text { superior }\end{array}$ & María Elena; Mauro Lo Coco & $\begin{array}{l}\text { Colección Biblioteca } \\
\text { Universitaria }\end{array}$ & 48 \\
\hline EUDEBA & $\begin{array}{l}\text { Nunca Más. Informe de la Comisión Nacio- } \\
\text { nal sobre la Desaparición de Personas }\end{array}$ & CONADEP & $\begin{array}{l}\text { Colección Derechos } \\
\text { Humanos }\end{array}$ & 47 \\
\hline UNQEditorial & $\begin{array}{l}\text { Ni gringos ni indios. Inmigración, criminali- } \\
\text { dad y racismo en la Argentina }\end{array}$ & Eugenia Scarzanella & $\begin{array}{l}\text { Colección Convergen- } \\
\text { cia. Entre Memoria y } \\
\text { Sociedad }\end{array}$ & 39 \\
\hline $\begin{array}{l}\text { EDUNLA } \\
\text { Cooperativa }\end{array}$ & $\begin{array}{l}\text { El peronismo de Perón a Kirchner. Una } \\
\text { pasión argentina }\end{array}$ & Bruno Susani & & 38 \\
\hline $\begin{array}{l}\text { UNIPE Ed. } \\
\text { Universitaria }\end{array}$ & $\begin{array}{l}\text { La muerte del Pibe Oscar (célebre escrus- } \\
\text { hiante) }\end{array}$ & Luis C. Villamayor & $\begin{array}{l}\text { Colección Boris } \\
\text { Spivacow }\end{array}$ & 36 \\
\hline $\begin{array}{l}\text { UNIRIO } \\
\text { Editora }\end{array}$ & Trabajo y salud mental & $\begin{array}{l}\text { Pablo Garaño; Constanza } \\
\text { Zelaschi; Marcelo Amable } \\
\text { (Comp.) }\end{array}$ & & 35 \\
\hline UNR Editora & Acústica y sistemas de sonido & Federico Miyara & & 35 \\
\hline UNAJ & $\begin{array}{l}\text { Introducción a la economía argentina. Una } \\
\text { visión desde la periferia }\end{array}$ & Gerardo De Santis & & 32 \\
\hline EDUNLU & Apuntes de historia y política del nivel inicial & $\begin{array}{l}\text { Noemí A. Simon, Rosana } \\
\text { E.Ponce, Ana Matilde Encabo } \\
\text { (Comp.) }\end{array}$ & $\begin{array}{l}\text { Colección Aulas uni- } \\
\text { versitarias }\end{array}$ & 30 \\
\hline EDUNER & $\begin{array}{l}\text { Las relaciones de género en la prostitución. } \\
\text { Construcción social de nuevas subjetivida- } \\
\text { des }\end{array}$ & $\begin{array}{l}\text { Nora Das Biaggio, Adriana } \\
\text { Vallejos, Zulma Lenarduzzi, } \\
\text { Isela Firpo }\end{array}$ & Serie Académica & 29 \\
\hline EDUNTREF & Afiches del Peronismo. 1945-1955 & $\begin{array}{l}\text { Raquel Quintana y Raúl } \\
\text { Manrupe. }\end{array}$ & $\begin{array}{l}\text { Colección Arte y } \\
\text { Cultura }\end{array}$ & 28 \\
\hline EUDEM & Socialismo y democracia & $\begin{array}{l}\text { Alfredo Remo Lazzeretti y } \\
\text { Fernando M. Suárez (Coord.) }\end{array}$ & $\begin{array}{l}\text { Otros libros del fondo } \\
\text { editorial }\end{array}$ & 27 \\
\hline EDULP & $\begin{array}{l}\text { Una erótica sangrienta. Literatura y sadoma- } \\
\text { soquismo }\end{array}$ & José Amícola (Comp.) & $\begin{array}{l}\text { Col. Sociales. Serie } \\
\text { Género }\end{array}$ & 26 \\
\hline UNSAM Edita & Michel Foucault y la política & Luciano Nosetto & Col. Ciencias Sociales & 26 \\
\hline Ed. UNICEN & $\begin{array}{l}\text { Iniciación a la lectura y a la escritura univer- } \\
\text { sitarias }\end{array}$ & $\begin{array}{l}\text { María Silvina Delbueno de } \\
\text { Prat }\end{array}$ & Colección Enseñanza & 24 \\
\hline $\begin{array}{l}\text { UNDAV } \\
\text { Ediciones }\end{array}$ & Una década ganada & $\begin{array}{l}\text { Santiago Fraschina, Arturo } \\
\text { Trinelli }\end{array}$ & $\begin{array}{l}\text { Col. Observatorio de } \\
\text { Políticas Públicas. } \\
\text { Serie Economía }\end{array}$ & 22 \\
\hline $\begin{array}{l}\text { CEDI-UNNO- } \\
\text { BA }\end{array}$ & Presente. Relatos de ex combatientes & VVAA (sin referencias) & Colección Testimonios & 21 \\
\hline EDIUNS & $\begin{array}{l}\text { Déspotas, invasores, usurpadores y Anar- } \\
\text { quistas. Representaciones rioplantenses de } \\
\text { los 'otros': enemigos y extranjeros durante } \\
\text { las primeras décadas del siglo XIX }\end{array}$ & Carmen Susana Cantera & $\begin{array}{l}\text { Serie Extensión: } \\
\text { Estudios Sociales y } \\
\text { Humanidades }\end{array}$ & 20 \\
\hline $\begin{array}{l}\text { Ediciones } \\
\text { UNL }\end{array}$ & Operaciones financieras & Norberto Tomas & Colección Cátedras & 19 \\
\hline $\begin{array}{l}\text { Editorial de la } \\
\text { UNC }\end{array}$ & Agustín Tosco. Textos reunidos 1953.1972 & Agustín Tosco & $\begin{array}{l}\text { Colección Sociedad. } \\
\text { Serie Textos Reunidos }\end{array}$ & 18 \\
\hline Ed. de la UNC & $\begin{array}{l}\text { El joven Borges y el expresionismo literario } \\
\text { alemán }\end{array}$ & Carlos García & Colección Ensayo & 18 \\
\hline
\end{tabular}




\begin{tabular}{|c|c|c|c|c|}
\hline N.E.U. & El payador perseguido & Atahualpa Yupanqui & $\begin{array}{l}\text { Atahualpa Yupanqui } \\
\text { Obras Completas }\end{array}$ & 17 \\
\hline $\begin{array}{l}\text { Editorial } \\
\text { UNRN }\end{array}$ & $\begin{array}{l}\text { Parentesco y política Topologías indígenas } \\
\text { en la Patagonia }\end{array}$ & Claudia Brione; Ana Ramos & Colección Aperturas & 17 \\
\hline EDUNLPAM & Espacios métricos & $\begin{array}{l}\text { María Eva Ascheri; Marisa } \\
\text { Reid }\end{array}$ & $\begin{array}{l}\text { Libros de Textos para } \\
\text { Estudiantes Universi- } \\
\text { tarios }\end{array}$ & 16 \\
\hline EDUNSE & $\begin{array}{l}\text { Quichuas, picardías y zorros. Conflictos y } \\
\text { tácticas en una comunidad bilingüe }\end{array}$ & Héctor Andreani & $\begin{array}{l}\text { Colección Sociedad y } \\
\text { Cultura }\end{array}$ & 16 \\
\hline EUNSA & Manual de didáctica especial de la química & Ana Varillas & & 13 \\
\hline EDIUNJU & $\begin{array}{l}\text { Reflexiones desde la psicología social. He- } \\
\text { rramientas para transformar la realidad }\end{array}$ & $\begin{array}{l}\text { Patricia Mendoza, Natalia } \\
\text { Ríos (Dir.) }\end{array}$ & $\begin{array}{l}\text { Colección Libros de } \\
\text { Cátedra }\end{array}$ & 12 \\
\hline EDIUNJU & $\begin{array}{l}\text { Epistemología. Introducción a la problemá- } \\
\text { tica }\end{array}$ & Beatriz Bruce & Col. Libros de Cátedra & 12 \\
\hline EDUNT & Introducción a la filosofía & Manuel González Casas & Colección Centenario & 12 \\
\hline $\begin{array}{l}\text { Ediciones } \\
\text { UNTDF }\end{array}$ & La cárcel de Ushuaia & Roberto Garriz & $\begin{array}{l}\text { Colección De Eso No } \\
\text { Se Habla }\end{array}$ & 12 \\
\hline $\begin{array}{l}\text { UNLaM } \\
\text { Editorial }\end{array}$ & En torno a la educación física & $\begin{array}{l}\text { Roberto Glina y Enrique } \\
\text { Daniel Silva (Comp.) }\end{array}$ & & 11 \\
\hline EDUNAM & $\begin{array}{l}\text { El papel de las mujeres paraguayas en la } \\
\text { Guerra del Chaco (1932-1935). Relaciones de } \\
\text { género en contexto bélico }\end{array}$ & Estela Mary Sosa & Colección Los Tesistas & 11 \\
\hline EUDENE & $\begin{array}{l}\text { Vientos y tempestades: violencia en la } \\
\text { periferia de la globalización. }\end{array}$ & $\begin{array}{l}\text { Jorge Prospero Roze, Maxi- } \\
\text { miliano Román, Marcelo } \\
\text { Graciosi, David Hernán Luna }\end{array}$ & $\begin{array}{l}\text { Colección Cosmo- } \\
\text { grafías }\end{array}$ & 10 \\
\hline EDUTECNE & Matemática Discreta & $\begin{array}{l}\text { Malva Alberto, Ingrid Schwer, } \\
\text { Yanina Fumero, Pamela Llop, } \\
\text { María Chara }\end{array}$ & & 9 \\
\hline UNDEF Libros & $\begin{array}{l}\text { Escenarios mundiales. Situaciones y con- } \\
\text { flictos }\end{array}$ & Ángel Pablo Tello & & 8 \\
\hline E.C.U. & Desde atrás del alambrado & Patricia Verónica Lobos & & 7 \\
\hline E.F.U. & Intimidades del San Juan profundo & Alfredo O. Miolano & & 4 \\
\hline EDUPA & $\begin{array}{l}\text { (Des)-Haciendo matemáticas: desde Pitágo- } \\
\text { ras a Descartes }\end{array}$ & Gabriel Soto & Serie Docencia & 3 \\
\hline EDUCO & Inseguridades & Roberto Samar (Comp.) & & 3 \\
\hline
\end{tabular}

Fuente: elaboración propia a partir de la información relevada Feria 2014-2017 por la LUA

En 2018 (tal como demuestra el Gráfico 3) los títulos sobre Educación -UNIPE Editorial Universitaria, EUDEM, EDUNLU, EDUNT, Editorial UNLZ- y también Derechos Humanos -UNSAM Edita, Ediciones UNDTF, UNQ Editorial, N.E.U., Editorial de la UNR- son los que preponderaron en las ventas del stand colectivo. Otros subgéneros importantes han sido Género(s) que continuó siendo central en tres editoriales -Ediciones UNGS, EDUVIM, EDUNER-; Literatura-EDIUNS, EDUNLA Cooperativa, Editorial UNICEN, EUDEBA; Antropología -Editorial UNRN, EDUNAM, E.C.U.- y Música-EUDENE, N.E.U.- Esas posiciones han sido seguidas por los libros de Política-UNIRIO Editora, Ediciones UNL, UNDEF Libros-, entre los más elegidos. El resto de los libros más vendidos corresponden a subgénero(s) que no llegan a tener relevancia significativa. 


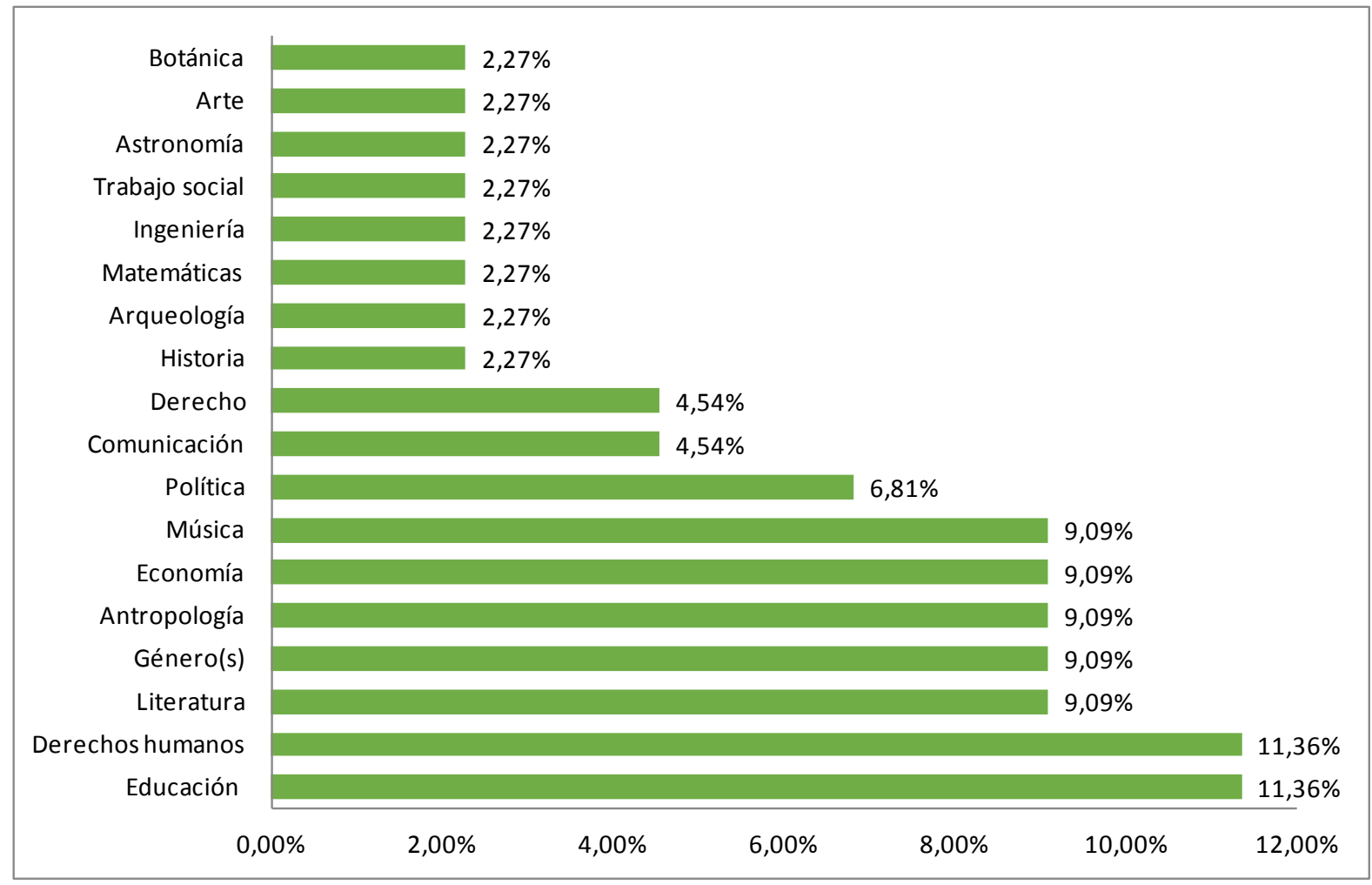

Fuente: elaboración propia a partir de la información relevada Feria 2018 por la LUA

Gráfico 3. Subgéneros más vendidos en 2018

Si bien el gráfico anterior muestra las grandes tendencias en las elecciones en la compra de títulos, por sello los libros orientados a la cursada académica, como el manual de EDUNPAZ y el título editado por la Editorial de la UNRN, las han posicionado entre los primeros lugares (Cuadro 5). Asimismo, en Literatura destacan los de EDUNLA Cooperativa y EUDEBA -esta última, reeditó en 201410 de los 50 títulos de "Los cuentos del Chiribitil" (Mihal y García, 2020)- que estuvieron dirigidos a las infancias, lo cual demuestra la diversidad de producciones y públicos a las que destinan sus ediciones las editoriales universitarias argentinas. Se reiteran casos como el de EDUNAM, N.E.U, EDUNLU, UNLAM y UNDEF Libros, en los que no hay un título que se destaque más, sino que tienen varios con la misma cantidad de ventas de ejemplares. Algunos sellos han logrado captar al público en subgéneros específicos durante el transcurso de algunos años-EDUNTREF9 con el Arte- $\mathrm{o}$ en las coediciones -Libros UNA, Editorial UADER ${ }^{10}{ }^{-}$.
9. Es una edición bilingüe no disponible en las categorías descriptoras del catálogo online en 2019, tampoco se daba cuenta si dicho título estaba descatalogado. La misma dificultad se encuentra con el libro más vendido por el sello de la Universidad Nacional de San Juan, que tampoco se encuentra en el catálogo

10. No está presente en ninguno de los cuadros mencionados, porque su comercialización en la Feria se llevó a cabo en coedición con las editoriales de Universidad Nacional del Litoral y con la Universidad Nacional de Córdoba, sin resultar significativos en la cantidad de ejemplares vendidos. 
Cuadro 5. Principales títulos vendidos en 2018

\begin{tabular}{|c|c|c|c|c|}
\hline Editorial & Título & Autoría & Clasificación & Cant \\
\hline EDUVIM & $\begin{array}{l}\text { La revolución de las mujeres. No era sólo una } \\
\text { píldora }\end{array}$ & Luciana Peker & $\begin{array}{l}\text { Colección Proyectos } \\
\text { Especiales }\end{array}$ & 115 \\
\hline $\begin{array}{l}\text { Ediciones } \\
\text { UNGS }\end{array}$ & Yo nena, yo princesa & Gabriela Mansilla & $\begin{array}{l}\text { Colección } \\
\text { Intervenciones }\end{array}$ & 42 \\
\hline UNSAM Edita & Clubes de futbol en tiempos de dictadura & $\begin{array}{l}\text { Mariano Gruschetsky, } \\
\text { Raanan Rein, Rodrigo Daskal } \\
\text { (Comp.) }\end{array}$ & $\begin{array}{l}\text { Colección Ciencias } \\
\text { Sociales }\end{array}$ & 42 \\
\hline EDUNPAZ & Manual de derecho colectivo del trabajo & Mariano Recalde & $\begin{array}{l}\text { Colección Morral de } \\
\text { Apuntes }\end{array}$ & 31 \\
\hline $\begin{array}{l}\text { Editorial } \\
\text { UNRN }\end{array}$ & $\begin{array}{l}\text { En el país de nomeacuerdo. Archivos y } \\
\text { memorias del genocidio del Estado argentino } \\
\text { sobre los pueblos originarios, 1780-1950 }\end{array}$ & $\begin{array}{l}\text { Walter Delrio; Marisa } \\
\text { Malvestitti; Diego Escolar; } \\
\text { Diana Lenton }\end{array}$ & Colección Aperturas & 30 \\
\hline EDIUNS & Ironía y humor en Jorge Luis Borges & $\begin{array}{l}\text { Marta Susana Domínguez } \\
\text { (Dir.) }\end{array}$ & $\begin{array}{l}\text { Serie Extensión: } \\
\text { Estudios Soc. y Hum. }\end{array}$ & 29 \\
\hline EDULP & Cuerpos minados. Masculinidades en Argentina & $\begin{array}{l}\text { José J. Maristany y Jorge L. } \\
\text { Peralta (Comp.) }\end{array}$ & $\begin{array}{l}\text { Col. Sociales. Serie } \\
\text { Género }\end{array}$ & 29 \\
\hline EUDENE & Rock correntino, pue & Javier “Pelo" Vallejos Amil & $\begin{array}{l}\text { Colección } \\
\text { Cosmografías }\end{array}$ & 19 \\
\hline $\begin{array}{l}\text { UNIRIO } \\
\text { Editora }\end{array}$ & $\begin{array}{l}\text { Sociedad, discursos y sujetos políticos. } \\
\text { Aproximación a la construcción de un discurso } \\
\text { político-académico }\end{array}$ & $\begin{array}{l}\text { Ramón Monteiro y María } \\
\text { Eugenia Álvarez (Comp.) }\end{array}$ & $\begin{array}{l}\text { Col. Académico- } \\
\text { Científica }\end{array}$ & 17 \\
\hline $\begin{array}{l}\text { UNIPE Ed. } \\
\text { Universitaria }\end{array}$ & $\begin{array}{l}\text { La política educativa en la Provincia de } \\
\text { Buenos Aires, 2001-2005. De la crisis a la } \\
\text { gobernabilidad }\end{array}$ & Daniel Lauría & $\begin{array}{l}\text { Col. Políticas } \\
\text { Educativas }\end{array}$ & 17 \\
\hline $\begin{array}{l}\text { Ediciones } \\
\text { UNL }\end{array}$ & $\begin{array}{l}\text { Identidades y poder. Tatuajes desafiantes de un } \\
\text { territorio en disputa }\end{array}$ & $\begin{array}{l}\text { María Elena Kessler; Marcos } \\
\text { E. Angeloni }\end{array}$ & Colección Diálogos & 16 \\
\hline EDUNER & $\begin{array}{l}\text { Las relaciones de género en la prostitución. } \\
\text { Construcción social de nuevas subjetividades }\end{array}$ & $\begin{array}{l}\text { Nora Das Biaggio, Adriana } \\
\text { Vallejos, Zulma Lenarduzzi, } \\
\text { Isela Firpo }\end{array}$ & Serie Académica & 16 \\
\hline $\begin{array}{l}\text { Ediciones } \\
\text { UNTDF }\end{array}$ & $\begin{array}{l}\text { Cartas de Alice Domon. Una desaparecida de la } \\
\text { dictadura argentina }\end{array}$ & Diana Viñoles & $\begin{array}{l}\text { Colección De eso no } \\
\text { se habla }\end{array}$ & 15 \\
\hline $\begin{array}{l}\text { Editorial de la } \\
\text { UNC }\end{array}$ & $\begin{array}{l}\text { Cultivo de plantas nativa propagación y } \\
\text { viverismo de especies de Argentina central }\end{array}$ & $\begin{array}{l}\text { Cecilia Eynard, Ana Calviño; } \\
\text { Lorena Ashworth }\end{array}$ & $\begin{array}{l}\text { Col. Ciencias. Serie } \\
\text { Naturales }\end{array}$ & 14 \\
\hline $\begin{array}{l}\text { EDUNLA } \\
\text { Cooperativa }\end{array}$ & El mundo que llegó tarde & Guillermo Tangelson & Fuera de Colección & 14 \\
\hline EUDEM & $\begin{array}{l}\text { Pedagogía(s) Vital (es). Cartografías del } \\
\text { pensamiento y gestos ético-políticos en } \\
\text { perspectiva descolonial }\end{array}$ & $\begin{array}{l}\text { Luis Porta; María Marta } \\
\text { Yedaide (Comp.) }\end{array}$ & $\begin{array}{l}\text { Colección } \\
\text { Indisciplina(s) }\end{array}$ & 13 \\
\hline UNQ Editorial & Quilmes, la brigada que fue pozo & Laura Rosso & $\begin{array}{l}\text { Col. Ediciones } \\
\text { Especiales }\end{array}$ & 13 \\
\hline EDIUNC & $\begin{array}{l}\text { En el cielo las estrellas. Mitos, historias y ciencia } \\
\text { en una astronomía para todos }\end{array}$ & Guillermo Abramson & Colección Ida y Vuelta & 12 \\
\hline Ed. UNICEN & El alemán de la Elena & Mariana Rodríguez & Col. Relatos & 11 \\
\hline $\begin{array}{l}\text { UNDAV } \\
\text { Ediciones }\end{array}$ & Lo dijo la radio. Entonces habrá que investigar & Lucía Casajús, Noelia Giorgi & $\begin{array}{l}\text { Colección Radio } \\
\text { Escrita }\end{array}$ & 11 \\
\hline UNM Editora & $\begin{array}{l}\text { Discusiones sobre el tipo de cambio. El eterno } \\
\text { retorno de lo mismo }\end{array}$ & Florencia Médici (ed.) & $\begin{array}{l}\text { Col. Biblioteca de } \\
\text { Economía }\end{array}$ & 10 \\
\hline EDUNLPAM & $\begin{array}{l}\text { Antología de la Antigua Compañía de Jesús: } \\
\text { carisma, instituciones y reducciones en } \\
\text { Paraguay, siglos XVI-XVIII }\end{array}$ & $\begin{array}{l}\text { María de la Soledad Justo, } \\
\text { Ignacio Zubizarreta }\end{array}$ & $\begin{array}{l}\text { Libros de Texto } \\
\text { para estudiantes } \\
\text { universitarios }\end{array}$ & 10 \\
\hline EDUNAM & $\begin{array}{l}\text { Tamboleros Dahomeyanos. Toques cubanos } \\
\text { para batería }\end{array}$ & Rafael Lezina & $\begin{array}{l}\text { Colección Fusas } \\
\text { Confusas }\end{array}$ & 10 \\
\hline
\end{tabular}




\begin{tabular}{|c|c|c|c|c|}
\hline EDUNAM & $\begin{array}{l}\text { Tamboleros Congos. Toques afrocubanos para } \\
\text { batería }\end{array}$ & Rafael Lezina & $\begin{array}{l}\text { Colección Fusas } \\
\text { Confusas }\end{array}$ & 10 \\
\hline N.E.U. & Aires indios & Atahualpa Yupanqui & $\begin{array}{l}\text { Atahualpa Yupanqui } \\
\text { Obras Completas }\end{array}$ & 10 \\
\hline N.E.U. & El canto del viento & Atahualpa Yupanqui & $\begin{array}{l}\text { Atahualpa Yupanqui } \\
\text { Obras Completas }\end{array}$ & 10 \\
\hline N.E.U. & $\begin{array}{l}\text { Memorias y vivencias de docentes de la UNSL } \\
\text { del golpe de estado } 1976\end{array}$ & $\begin{array}{l}\text { Gonzalo Pando; Elio Rodolfo } \\
\text { Parisí }\end{array}$ & & 10 \\
\hline EUDEBA & Nicolodo viaja al país de la cocina & Graciela Montes & $\begin{array}{l}\text { Col. Los Cuentos del } \\
\text { Chiribitil }\end{array}$ & 9 \\
\hline UNR Editora & $\begin{array}{l}\text { ¿Cómo fundar una comunidad después } \\
\text { del crimen? Una reflexión sobre el carácter } \\
\text { político del perdón y la reconciliación, a la luz } \\
\text { de los Juicios a las Juntas en Argentina y de la } \\
\text { Comisión de la Verdad y la Reconciliación en } \\
\text { Sudáfrica }\end{array}$ & Claudia Hilb & & 9 \\
\hline EDUNLU & Marcas del higienismo en el trabajo social & Roxana Basta & Col. Ciencias & 9 \\
\hline EDUNLU & $\begin{array}{l}\text { Educación, políticas públicas y hegemonía. } \\
\text { Aportes desde la Sociología de la Educación }\end{array}$ & Mariano Indart (Comp.) & $\begin{array}{l}\text { Colección Aulas } \\
\text { Universitarias }\end{array}$ & 9 \\
\hline EDUNTREF & Afiches del Peronismo. 1945-1955 & $\begin{array}{l}\text { Raquel Quintana y Raúl } \\
\text { Manrupe. }\end{array}$ & $\begin{array}{l}\text { Colección Arte y } \\
\text { Cultura }\end{array}$ & 7 \\
\hline EDUNSE & $\begin{array}{l}\text { La guitarra en Latinoamérica. Sonoridades } \\
\text { percutivas en obras del siglo XX }\end{array}$ & Karen Lucía Arango Higuita & $\begin{array}{l}\text { Colección } \\
\text { Convergencias }\end{array}$ & 7 \\
\hline UNAJ & $\begin{array}{l}\text { Introducción a la Economía Argentina. Una } \\
\text { visión desde la periferia }\end{array}$ & Gerardo De Santis & & 6 \\
\hline EDUNT & $\begin{array}{l}\text { Julio Prebisch: Primer rector de la Reforma } \\
\text { Universitaria }\end{array}$ & Miguel Isas (Comp.) & Colección Centenario & 5 \\
\hline E.C.U. & $\begin{array}{l}\text { Sabor a saber Mapuche. Difusión y } \\
\text { revalorización del Kimun }\end{array}$ & $\begin{array}{l}\text { Nilda Brutti, Antolín } \\
\text { Cárdenas, José Cayún, B. } \\
\text { Conte, Elisa Ose, Cristina } \\
\text { Possidoni, Elda Trigos, P. } \\
\text { Garramuño, L. Carvante } \\
\end{array}$ & & 5 \\
\hline EDUTECNE & Matemática Discreta & $\begin{array}{l}\text { Alberto Malva, Ingrid Schwer, } \\
\text { Yanina Fumero, Pamela Llop, } \\
\text { María Chara }\end{array}$ & & 4 \\
\hline $\begin{array}{l}\text { Editorial } \\
\text { UNLZ }\end{array}$ & $\begin{array}{l}\text { Enseñar y aprender en el campo reflexiones } \\
\text { sobre el sistema educativo en el ámbito rural }\end{array}$ & Oga Zattera & & 3 \\
\hline EDUCO & $\begin{array}{l}\text { Trabajadores y trabajadoras en la Argentina. } \\
\text { Aportes para una historia social }\end{array}$ & Enrique Mases (Comp.) & & 2 \\
\hline EDIUNJU & $\begin{array}{l}\text { Ecuaciones diferenciales y análisis en varias } \\
\text { variables. Un texto para carreras de Ingeniería }\end{array}$ & Gustavo A. Lores & $\begin{array}{l}\text { Colección Libros de } \\
\text { Cátedra }\end{array}$ & 2 \\
\hline UNLaM & $\begin{array}{l}\text { La radio en la escuela. Un recurso didáctico de } \\
\text { gran valor educativo }\end{array}$ & Juan C. Dido; Sergio Barberis & & 2 \\
\hline UNLaM & Liquidación de sueldos y jornales & $\begin{array}{l}\text { Elio Chaieb, Silvia Pettinato; } \\
\text { Jorge Robles }\end{array}$ & & 2 \\
\hline UNDEF Libros & Escenarios mundiales. Situaciones y conflictos & Ángel Pablo Tello & & 2 \\
\hline UNDEF Libros & Aportes para un nuevo Código Aeronáutico & Griselda Capaldo & & 2 \\
\hline EUNSA & $\begin{array}{l}\text { Arqueología de Cafayate, Salta un enfoque a } \\
\text { través de su cerámica y arte rupestre }\end{array}$ & $\begin{array}{l}\text { Rossana Ledesma, Claudia } \\
\text { Subelza }\end{array}$ & & 1 \\
\hline
\end{tabular}




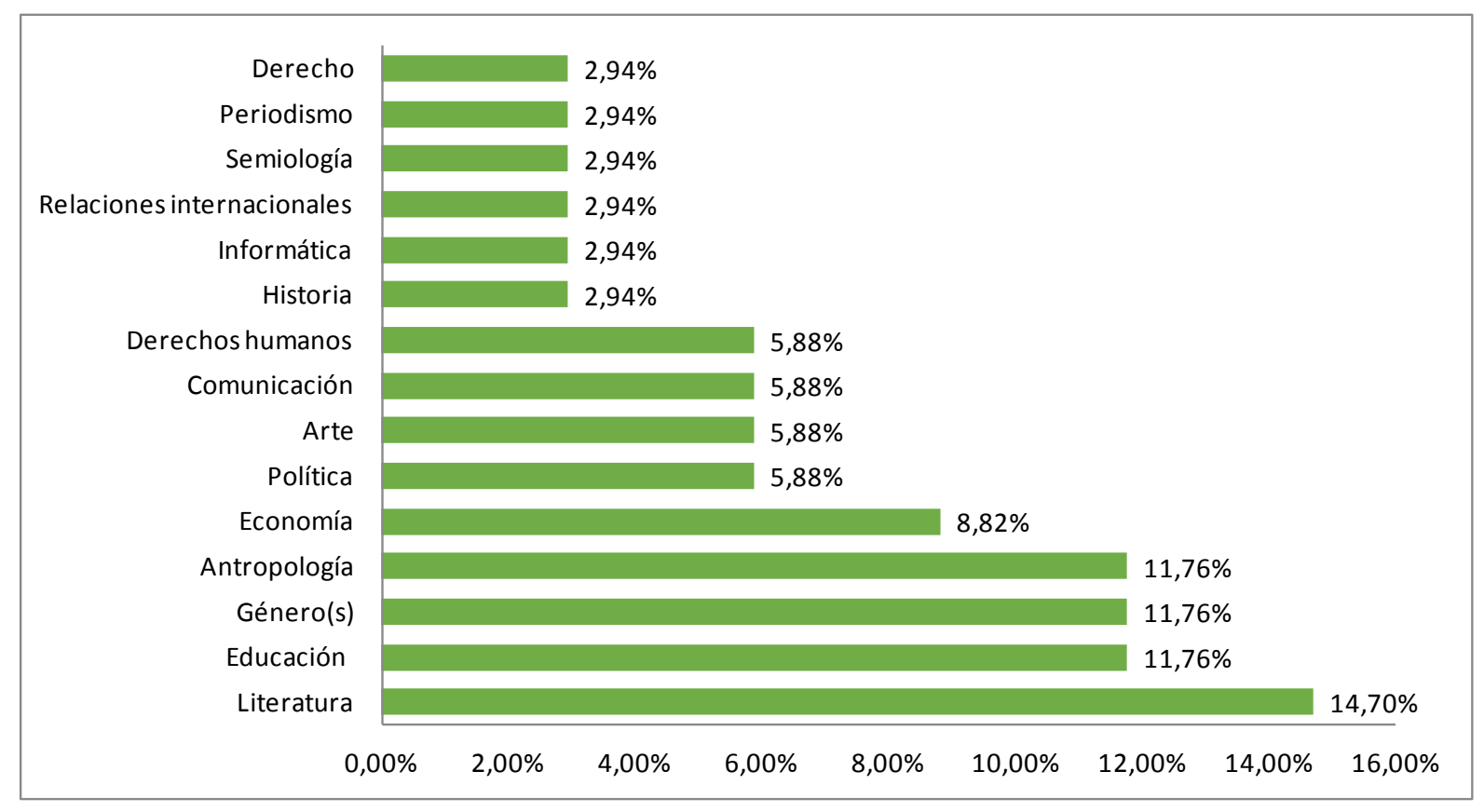

Gráfico 4. Subgéneros más vendidos en 2019
Fuente: elaboración propia a partir de la información relevada Feria 2019 por la LUA

2019 es el año en que el subgénero (Gráfico 4) más vendido fue el de Literatura -UNIPE Editorial Universitaria, EUDEM, EDUNER, UNIRIO Editora-, el cual involucra libros desde Crítica Literaria, Estudios sobre Literatura, hasta Poemas y Narrativa. En este año tanto como en 2018 (Gráfico 3), Educación fue otro de los más elegidos -EDIUNC, UNAJ, UNIRIO Editora, UNAHUR-, concentrándose en temas de Educación Superior, lo cual posiblemente se vincule con el centenario de la Reforma Universitaria en 2018 en Argentina, año en el marco del cual se llevaron a cabo numerosas instancias colectivas de reflexión, algunas de las cuales se plasman en los títulos solicitados. A estos le siguieron Antropología -Editorial UNRN, UNICEN Editorial, EDUNSE, EDUNAM- y Género(s) -UNSAM Edita, EDUNLU, EDIUNJU-entre los más vendidos. Por debajo se encuentra Economía -EDULP, UNM Editora y UNDAV Ediciones-y muy por debajo los otros subgéneros. UNIRÍO Editora y EDIUNJU han tenido dos libros de distintas colecciones posicionados como primero en sus ventas.

Se trata entonces 2019 de un año que muestra ciertas particularidades que refieren tanto a movimientos en la comercialización como en los sellos que la encabezan. En este sentido, dos editoriales cuyas trayectorias son bastante recientes como UNIPE Editorial Universitaria y Ediciones UNTDF lideran las ventas en cantidad de ejemplares de dos títulos, el primero sobre Crítica Literaria, y el segundo sobre Derechos Humanos (Cuadro 6).

Por otra parte, el análisis muestra en 2018 y 2019 una diversificación de los títulos correspondientes al área de las Ciencias Naturales y Exactas. Si entre 2014-2017, predominaba Matemáticas -EDULPAM, EDUTECNE, EDUPA-, otros subgéneros emergen como Astronomía, Ingeniería, Informática, aunque sin representar un número significativo en el grueso de la comercialización. Desde 2014 a 2019 inclusive otros subgéneros como Comunicación, Economía, Arqueología, Derecho, Salud, Semiología, Relaciones Internacionales, siendo secundarios en venta han formado parte en mayor o menor medida de las adquisiciones en el marco de la feria. 
Cuadro 6. Títulos más vendidos en 2019

\begin{tabular}{|c|c|c|c|c|}
\hline Editorial & Título & Autoría & Clasificación & Cant. \\
\hline $\begin{array}{l}\text { UNIPE Ed. } \\
\text { Universitaria }\end{array}$ & Walsh, 1957. Acerca de Operación Masacre & Vicente Battista & Colección Autor/Fecha & 39 \\
\hline $\begin{array}{l}\text { Ediciones } \\
\text { UNTDF }\end{array}$ & Identidad. Educar en la memoria & Claudio Altamirano & $\begin{array}{l}\text { Colección De Eso No } \\
\text { Se Habla }\end{array}$ & 38 \\
\hline $\begin{array}{l}\text { EDUNLA } \\
\text { Cooperativa }\end{array}$ & $\begin{array}{l}\text { El pensamiento de Francisco. Reflexiones desde } \\
\text { y para América Latina }\end{array}$ & Nerio Neirotti (Coord.) & Fuera de Colección & 36 \\
\hline UNSAM Edita & $\begin{array}{l}\text { Feminismos, género y transgénero. Breve } \\
\text { historia desde el siglo XIX hasta nuestros días }\end{array}$ & Vanesa Vázquez Laba & $\begin{array}{l}\text { Colección Cuadernos } \\
\text { de Cátedra }\end{array}$ & 35 \\
\hline EDULP & $\begin{array}{l}\text { Pasaron cosas: nuevo fracaso del } \\
\text { neoliberalismo financiero en Argentina }\end{array}$ & Santiago Fraschina (Comp.) & & 30 \\
\hline EDIUNC & $\begin{array}{l}\text { La investigación científica argentina en } \\
\text { dictadura. Transferencias y desplazamientos de } \\
\text { recursos (1974-1983) }\end{array}$ & Fabiana Bekerman & $\begin{array}{l}\text { Colección } \\
\text { Indagaciones }\end{array}$ & 28 \\
\hline Ediciones UNGS & José Ber Gelbard: la patria desde el boliche & Julián Blejmar & $\begin{array}{l}\text { Colección Pensadores } \\
\text { de América Latina }\end{array}$ & 26 \\
\hline UNM Editora & $\begin{array}{l}\text { Piero Sraffa: los fundamentos de la teoría } \\
\text { clásica del excedente }\end{array}$ & Alejandro Fiorito & $\begin{array}{l}\text { Colección Biblioteca } \\
\text { de Economía }\end{array}$ & 26 \\
\hline UNAJ & Universidad y nación. Asignaturas pendientes & Ernesto Villanueva & & 26 \\
\hline EDUVIM & $\begin{array}{l}\text { Actores, políticas públicas y conflicto } \\
\text { agropecuario }\end{array}$ & Marcelo Panero (Comp.) & $\begin{array}{l}\text { Colección Proyectos } \\
\text { Especiales }\end{array}$ & 24 \\
\hline Editorial UNRN & $\begin{array}{l}\text { En el país de nomeacuerdo. Archivos y } \\
\text { memorias del genocidio del Estado argentino } \\
\text { sobre los pueblos originarios, } 1780-1950\end{array}$ & $\begin{array}{l}\text { Walter Delrio, Marisa } \\
\text { Malvestitti, Diego Escolar, } \\
\text { Diana Lenton }\end{array}$ & Colección Aperturas & 20 \\
\hline EDUNLU & $\begin{array}{l}\text { Género, saberes y labores de las sociedades } \\
\text { Indígenas Pampeano- Patagónicas }\end{array}$ & $\begin{array}{l}\text { Mabel M. Fernández } \\
\text { (Comp.) }\end{array}$ & & 19 \\
\hline EDUNPAZ & $\begin{array}{l}\text { La Constitución maldita. Estudios sobre la } \\
\text { reforma de } 1949\end{array}$ & Mauro Benete (Comp.) & $\begin{array}{l}\text { Colección Pensamiento } \\
\text { Nacional }\end{array}$ & 19 \\
\hline EUDEM & Latinoamérica entre lenguajes y lenguas & $\begin{array}{l}\text { Mónica Marinone, Gabriela } \\
\text { Tineo (Coord.) }\end{array}$ & $\begin{array}{l}\text { Serie Símbolos: } \\
\text { Human. y Cs Sociales }\end{array}$ & 19 \\
\hline $\begin{array}{l}\text { Editorial } \\
\text { UNICEN }\end{array}$ & $\begin{array}{l}\text { Buenos Aires indígena: cartografía social de los } \\
\text { invisible }\end{array}$ & Inés Rosso & Colección Sociedad & 19 \\
\hline EDUNSE & $\begin{array}{l}\text { Morir en el monte. Los rituales fúnebres de } \\
\text { Santiago del Estero en su expresión polisémica }\end{array}$ & Maricel Pelegrín & $\begin{array}{l}\text { Colección Ciencia y } \\
\text { Técnica }\end{array}$ & 17 \\
\hline $\begin{array}{l}\text { Editorial de la } \\
\text { UNQ }\end{array}$ & $\begin{array}{l}\text { La voz de la mujer. Periódico comunista- } \\
\text { anarquista 1896-1897 }\end{array}$ & & $\begin{array}{l}\text { Colección La Ideología } \\
\text { Argentina }\end{array}$ & 14 \\
\hline EDUNER & En constante inconstancia & Marilyn Contardi & $\begin{array}{l}\text { Aura Colección } \\
\text { Contemporánea }\end{array}$ & 14 \\
\hline Ed. de la UNC & Ojos de la palabra & Jorge Boccanera & Colección Formas & 13 \\
\hline UNIRIO Ed. & La revolución de las conciencias & Guillermo Ricca (Comp.) & Colección: 45/50 años & 13 \\
\hline UNIRIO Editora & $\begin{array}{l}\text { De cómo llegó la nieve. Volumen } 1 \text { de la Balada } \\
\text { del desterrado }\end{array}$ & Antonio Tello & $\begin{array}{l}\text { Colección: De La } \\
\text { Eterna memoria }\end{array}$ & 13 \\
\hline EDUNTREF & Construcción de software: una mirada ágil & $\begin{array}{l}\text { Nicolás Paez, Diego } \\
\text { Fontdevila (Ed.) }\end{array}$ & Informática & 11 \\
\hline EDIUNJU & $\begin{array}{l}\text { Las que cantan. El copleo femenino en Jujuy: } \\
\text { historia y relato }\end{array}$ & María Eduarda Mirande & $\begin{array}{l}\text { Col. Producción } \\
\text { Científica/ Resultados }\end{array}$ & 10 \\
\hline EDIUNJU & $\begin{array}{l}\text { La comunicación digital. Redes sociales, } \\
\text { nuevas audiencias y convergencias: desafíos y } \\
\text { oportunidades para la industria, el Estado y los } \\
\text { usuarios }\end{array}$ & María Eduarda Mirande & Colección Varios & 10 \\
\hline UNDEF Libros & $\begin{array}{l}\text { China, Rusia e India en América Latina: un } \\
\text { enfoque multidimensional }\end{array}$ & LLenderrozas, Elsa & & 10 \\
\hline
\end{tabular}




\begin{tabular}{|l|l|l|l|c|}
\hline UNR Editora & Semiólogos, críticos y populistas & Ricardo Diviani & 10 \\
\hline EUDEBA & $\begin{array}{l}\text { Nunca Más. Informe de la Comisión Nacional } \\
\text { sobre la Desaparición de Personas }\end{array}$ & CONADEP & $\begin{array}{l}\text { Colección Derechos } \\
\text { Humanos }\end{array}$ & 9 \\
\hline UNDAV Ed. & Teletrabajo hoy. Actualidad y desafíos & Gabriel Maresca & Fuera de Colección & 9 \\
\hline EDUNAM & $\begin{array}{l}\text { Primer Diccionario Mbya-Ayvu-Español / } \\
\text { Español-Mbya Guaraní }\end{array}$ & José J. Rodas & & 8 \\
\hline Ed. UNRAF & Cultura libre: crear, modificar, compartir & Esteban Magnani & Colección Medios & 8 \\
\hline UNAHUR & $\begin{array}{l}\text { A 1oo años de la Reforma Universitaria. } \\
\text { Hurlingham }\end{array}$ & $\begin{array}{l}\text { Jaime Erczyk; Pablo } \\
\text { Buchbinder; Adriana } \\
\text { Puiggrós; Alberto Sileoni; } \\
\text { Alberto Kornblihtt; Jorge } \\
\text { Aliaga; Sergio Balardini; } \\
\text { Alejandro Grimson }\end{array}$ & Eriversidad Nacional de & 7 \\
\hline Libros UNA & $\begin{array}{l}\text { Manual de trapecio fijo técnica en las artes del } \\
\text { circo }\end{array}$ & Erica Stoppel & Colección Manuales & 5 \\
\hline EDUNT & Arte contemporáneo: de marcos y marcas & Jorge Figueroa & $\begin{array}{l}\text { Colección Saberes } \\
\text { Académicos }\end{array}$ & 5 \\
\hline NEU & Primavera rota & Oscar Ángel Flores & 5 & 4 \\
\hline
\end{tabular}

11. Zamba era uno de los personajes principales de la programación del Canal Paka Paka, señal pública surgida en 2010, la cual se orientaba a las infancias y dependía del Ministerio de Educación de la Nación.
En cuanto a las coediciones, se han referenciado las más relevantes en relación con la cantidad de ejemplares vendidos, y a lo largo de los años es posible observar diferencias. Entre 2014-2017 los libros coeditados por universidades nacionales (Cuadro 7), dentro del subgénero Literatura han sido una de las elecciones más específicas. El libro coeditado con más venta dentro del stand colectivo ha sido el de EDULP y EDIUNJU con el personaje que se emitía por el canal de televisión pública, denominado Zamba ${ }^{11}$, cuya venta no se ha superado hasta el momento. Este libro que apuntaba a generar una colección sobre Literatura Infantil y Juvenil a través de distintos títulos que tuvieran como protagonista al personaje fue presentado en la Feria de 2015, pero según el director editorial de EDULP "la colección no se pudo continuar y ese libro fue retirado del catálogo y de la venta al público por pedido del Ministerio de Educación" (comunicación personal, 29 de noviembre 2019). La serie El País del Sauce coeditada por dos universidades del centro del país, UNL Ediciones y EDUNER, se ha posicionado fuertemente en la comercialización con la edición de obras de autores argentinos reconocidos en el campo literario. 
Cuadro 7. Coediciones más vendidas en el período 2014-2017

\begin{tabular}{|c|c|c|c|c|c|}
\hline Editoriales & Sub-género & Título & Autoría & Clasificación & Cant. \\
\hline EDULP y EDIUNJU & Literatura & $\begin{array}{l}\text { El Asombroso libro de Zamba en las } \\
\text { Islas Malvinas }\end{array}$ & & & 63 \\
\hline $\begin{array}{l}\text { EDUNER y UNL } \\
\text { Ediciones }\end{array}$ & Literatura & El país del río. Aguafuertes y crónicas & $\begin{array}{l}\text { Roberto Arlt y Rodolfo } \\
\text { Walsh }\end{array}$ & $\begin{array}{l}\text { Serie El país del } \\
\text { sauce }\end{array}$ & 48 \\
\hline $\begin{array}{l}\text { EDUNER y UNL } \\
\text { Ediciones }\end{array}$ & Literatura & El Junco y la corriente & Juan L. Ortiz & $\begin{array}{l}\text { Serie El país del } \\
\text { sauce }\end{array}$ & 48 \\
\hline $\begin{array}{l}\text { UNIPE Editorial } \\
\text { Universitaria y } \\
\text { Centro de Estudios e } \\
\text { Investigación Dr. A. } \\
\text { Jauretche }\end{array}$ & Política & Pensar a Jauretche & $\begin{array}{l}\text { Gustavo Marangoni } \\
\text { (comp.) }\end{array}$ & $\begin{array}{l}\text { Col. Volúmenes } \\
\text { Especiales y } \\
\text { Coediciones }\end{array}$ & 39 \\
\hline $\begin{array}{l}\text { Ediciones UNGS- } \\
\text { Imago Mundi }\end{array}$ & Comunicación & $\begin{array}{l}\text { La sonrisa de mamá es como la de } \\
\text { Perón. Capusotto: realidad política } \\
\text { y cultura }\end{array}$ & $\begin{array}{l}\text { Rocco Carbone } \\
\text { y Matías Muraca } \\
\text { (Comp.) }\end{array}$ & $\begin{array}{l}\text { Col. } \\
\text { Comunicación, } \\
\text { Artes y Cultura }\end{array}$ & 28 \\
\hline $\begin{array}{l}\text { Editorial UNRN- } \\
\text { Guionarte }\end{array}$ & Cine & $\begin{array}{l}\text { El método Guionarte Guión y } \\
\text { creatividad I }\end{array}$ & Michelina Oviedo & $\begin{array}{l}\text { Categoría } \\
\text { Coediciones }\end{array}$ & 26 \\
\hline $\begin{array}{l}\text { Ediciones UNGS- } \\
\text { Universidad } \\
\text { Nacional Autónoma } \\
\text { de México }\end{array}$ & Género(s) & $\begin{array}{l}\text { Subordinaciones invertidas. Sobre el } \\
\text { derecho a la identidad de género }\end{array}$ & $\begin{array}{l}\text { Laura Saldivia } \\
\text { Menajovsky }\end{array}$ & $\begin{array}{l}\text { Colección Política, } \\
\text { Políticas y } \\
\text { Sociedad }\end{array}$ & 16 \\
\hline $\begin{array}{l}\text { Ediciones UNGS y } \\
\text { Prometeo }\end{array}$ & Historia & $\begin{array}{l}\text { Historia, ¿para qué? Revisitas a una } \\
\text { vieja pregunta }\end{array}$ & $\begin{array}{l}\text { Jorge Cernadas y } \\
\text { Daniel Lvovich (Ed.) }\end{array}$ & $\begin{array}{l}\text { Colección } \\
\text { Humanidades }\end{array}$ & 15 \\
\hline $\begin{array}{l}\text { Editorial de la UNC y } \\
\text { El Cíclope Ediciones }\end{array}$ & Política & No matar: sobre la responsabilidad & $\begin{array}{l}\text { Belzagui, Pablo René } \\
\text { (comp.) }\end{array}$ & Colección Política & 14 \\
\hline $\begin{array}{l}\text { EDUNLU y MOCASE } \\
\text { Vía Campesina }\end{array}$ & Historia & $\begin{array}{l}\text { Memoria de los orígenes de la } \\
\text { Central Campesina de Productores } \\
\text { del Norte }\end{array}$ & $\begin{array}{l}\text { MOCASE - Vía } \\
\text { Campesina }\end{array}$ & $\begin{array}{l}\text { Col. Sociedad en } \\
\text { Movimiento }\end{array}$ & 14 \\
\hline $\begin{array}{l}\text { UNDAV Ed. y } \\
\text { Asociación Argentina } \\
\text { de la Ciencia del } \\
\text { Suelo, Asociación } \\
\text { Geológica Argentina }\end{array}$ & Geología & $\begin{array}{l}\text { Suelos y geología argentina. Una } \\
\text { visión integradora desde diferentes } \\
\text { campos disciplinarios }\end{array}$ & $\begin{array}{l}\text { Fernando Pereyra y } \\
\text { Martín Torres Duggan } \\
\text { (Comp.) }\end{array}$ & $\begin{array}{l}\text { Colección Región y } \\
\text { Ambiente }\end{array}$ & 13 \\
\hline EDIUNS y NOVEDUC & Educación & $\begin{array}{l}\text { Debates universitarios acerca de lo } \\
\text { didáctico y la formación docente. } \\
\text { Didáctica general y didácticas } \\
\text { específicas. Estrategias de enseñanza. } \\
\text { Ambientes de aprendizaje }\end{array}$ & $\begin{array}{l}\text { Elda Monetti y Ana } \\
\text { María Malett (Comp.) }\end{array}$ & $\begin{array}{l}\text { Serie Extensión: } \\
\text { Ciencia y } \\
\text { Tecnología }\end{array}$ & 13 \\
\hline $\begin{array}{l}\text { Ediciones UNGS y } \\
\text { Prometeo }\end{array}$ & Economía & $\begin{array}{l}\text { Reconfiguraciones del mundo } \\
\text { popular. El Conurbano Bonaerense } \\
\text { en la postconvertibilidad }\end{array}$ & $\begin{array}{l}\text { Gabriel Kessler, } \\
\text { Maristella Svampa, } \\
\text { Inés González Bombal } \\
\text { (Coord.) }\end{array}$ & $\begin{array}{l}\text { Colección Política, } \\
\text { Políticas y } \\
\text { Sociedad }\end{array}$ & 13 \\
\hline $\begin{array}{l}\text { UNDAV Ediciones y } \\
\text { Ediciones UNGS }\end{array}$ & Historia & $\begin{array}{l}\text { Gramáticas plebeyas. Populismo, } \\
\text { democracia y nuevas izquierdas en } \\
\text { América Latina. }\end{array}$ & $\begin{array}{l}\text { Claudio Véliz y Ariana } \\
\text { Reano (Comp.) }\end{array}$ & $\begin{array}{l}\text { Col. Gramáticas } \\
\text { Plebeyas }\end{array}$ & 13 \\
\hline $\begin{array}{l}\text { UNDAV Ediciones y } \\
\text { Ediciones UNGS }\end{array}$ & Historia & $\begin{array}{l}\text { Palabras Políticas. Debates sobre la } \\
\text { democracia en la argentina de los } \\
\text { ochenta. }\end{array}$ & $\begin{array}{l}\text { Ariana Reano y Julia } \\
\text { Smola }\end{array}$ & $\begin{array}{l}\text { Col. Gramáticas } \\
\text { Plebeyas }\end{array}$ & 12 \\
\hline $\begin{array}{l}\text { UNM Editora - } \\
\text { Municipalidad de } \\
\text { Moreno }\end{array}$ & $\begin{array}{l}\text { Derechos } \\
\text { Humanos }\end{array}$ & $\begin{array}{l}\text { Testimonios del terrorismo } \\
\text { de estado en Moreno y Merlo. } \\
\text { Memorias de sobrevivientes } \\
\text { y familiares de detenidos- } \\
\text { desaparecidos (Parte I) }\end{array}$ & $\begin{array}{l}\text { Natacha Misiak, } \\
\text { Alejandra Ballestero, } \\
\text { Miguel Fernández } \\
\text { (Coord.) }\end{array}$ & $\begin{array}{l}\text { Colección Agenda } \\
\text { UNM }\end{array}$ & 12 \\
\hline $\begin{array}{l}\text { Ediciones UNGS e } \\
\text { Instituto de Estudios } \\
\text { y Capacitación-IEC- } \\
\text { CONADU }\end{array}$ & Educación & $\begin{array}{l}\text { La internacionalización de la } \\
\text { universidad. Debates globales, } \\
\text { acciones regionales }\end{array}$ & Daniela Perrotta & $\begin{array}{l}\text { Colección } \\
\text { Educación: Serie } \\
\text { Universidad }\end{array}$ & 10 \\
\hline
\end{tabular}




\begin{tabular}{|l|l|l|l|l|l|}
\hline $\begin{array}{l}\text { Ediciones UNGS, } \\
\text { EDULP y EDUNAM }\end{array}$ & $\begin{array}{l}\text { Derechos } \\
\text { Humanos }\end{array}$ & $\begin{array}{l}\text { Lo aparente como real. Un análisis } \\
\text { del sujeto “comunista” en la } \\
\text { creación y consolidación del servicio } \\
\text { de inteligencia de la policía de la } \\
\text { Provincia de Buenos Aires (1930- } \\
1962)\end{array}$ & $\begin{array}{l}\text { María Eugenia } \\
\text { Marengo }\end{array}$ & $\begin{array}{l}\text { Colección Entre } \\
\text { los Libros de la } \\
\text { Buena Memoria }\end{array}$ \\
\hline $\begin{array}{l}\text { Libros UNA y } \\
\text { MALBA }\end{array}$ & Fotografía & Marcados Claudia Andújar & Agustín Pérez Rubio & Coedición \\
\hline
\end{tabular}

Fuente: elaboración propia a partir de la información relevada Feria 2014-2017 por la LUA

En 2018 (Cuadro 8) y 2019 (Cuadro 9) las coediciones fueron de subgéneros variados y en 2019 solo una de ellas, la de la Universidad Nacional de Córdoba reportó ventas significativas. Ediciones UNGS destaca por la cantidad y variedad de coeditores en sus títulos, y en relación con las coediciones entre editoriales universitarias se reiteran generalmente los sellos participantes. Por otra parte, algunos sellos como UNDAV Ediciones muestran cómo encontraron un espacio en la coedición con asociaciones civiles, editoriales independientes y universitarias, que le permiten realizar ventas y lograr incrementar su visibilidad en el espacio de la feria (más aun teniendo en cuenta que a diferencia de otros sellos no tiene librería propia). Lo mismo sucede con la Editorial de la UNRN que ha tenido más ventas en la coedición que en otros títulos, o con Libros UNA, cuya coedición con el MALBA fue su primer libro publicado.

Cuadro 8. Coediciones más vendidas en 2018

\begin{tabular}{|c|c|c|c|c|c|}
\hline Editoriales & Sub-género & Título & Autoría & Clasificación & Cant. \\
\hline $\begin{array}{l}\text { UNDAV Ediciones y } \\
\text { Ediciones UNGS }\end{array}$ & Economía & $\begin{array}{l}\text { Macrieconomía. El impacto del } \\
\text { neoliberalismo en la Argentina (vol. 1) }\end{array}$ & $\begin{array}{l}\text { Fernando Ausas, } \\
\text { Federico Basualdo, } \\
\text { Juan Fal, Santiago } \\
\text { Fraschina }\end{array}$ & $\begin{array}{l}\text { Colección } \\
\text { Observatorio } \\
\text { de Políticas } \\
\text { Públicas } \\
\end{array}$ & 19 \\
\hline $\begin{array}{l}\text { Editorial de la UNC y } \\
\text { UNIRÍO Editora }\end{array}$ & Educación & Juan Filloy. Papeles Sueltos & $\begin{array}{l}\text { Candelaria de } \\
\text { Olmos y Juan M. } \\
\text { Conforte (Comp.) } \\
\end{array}$ & $\begin{array}{l}\text { Colección } \\
\text { Reforma }\end{array}$ & 14 \\
\hline $\begin{array}{l}\text { UNDAV Ediciones y } \\
\text { Punto de Encuentro }\end{array}$ & Comunicación & $\begin{array}{l}\text { Libertad de Antena. La identidad } \\
\text { política de las radios comunitarias, } \\
\text { populares y alternativas argentinas } \\
(1983-2015)\end{array}$ & Laura Kejval & $\begin{array}{l}\text { Fuera de } \\
\text { Colección }\end{array}$ & 14 \\
\hline $\begin{array}{l}\text { UNDAV Ediciones y } \\
\text { Punto de Encuentro }\end{array}$ & Género(s) & $\begin{array}{l}\text { Hacia una criminología feminista. } \\
\text { Violencia, androcentrismo, justicia y } \\
\text { derechos humanos }\end{array}$ & Carmen Antony & $\begin{array}{l}\text { Col. } \\
\text { Criminología } \\
\text { Crítica }\end{array}$ & 13 \\
\hline $\begin{array}{l}\text { Ediciones UNGS y } \\
\text { EDUVIM }\end{array}$ & Educación & $\begin{array}{l}\text { Educación matemática: aportes a la } \\
\text { formación docente desde distintos } \\
\text { enfoques teóricos }\end{array}$ & $\begin{array}{l}\text { Marcel D. Pochulu y } \\
\text { Mabel A. Rodríguez } \\
\text { (Comp.) }\end{array}$ & $\begin{array}{l}\text { Colección } \\
\text { Educación }\end{array}$ & 12 \\
\hline $\begin{array}{l}\text { Ediciones UNL y } \\
\text { EUDEBA }\end{array}$ & Género(s) & $\begin{array}{l}\text { El tiempo no para. Los últimos } \\
\text { homosexuales cuentan la historia }\end{array}$ & Ernesto Meccia & $\begin{array}{l}\text { Col. Proyectos } \\
\text { Especiales }\end{array}$ & 10 \\
\hline $\begin{array}{l}\text { Editorial de la UNC } \\
\text { y Encuentro Grupo } \\
\text { Editor }\end{array}$ & Política & $\begin{array}{l}\text { Integración latinoamericana. } \\
\text { Experiencias }\end{array}$ & $\begin{array}{l}\text { Jacquelina Brizzio; } \\
\text { Santiago Espósito; } \\
\text { José Emilio Ortega }\end{array}$ & $\begin{array}{l}\text { Colección } \\
\text { Sociedad }\end{array}$ & 10 \\
\hline
\end{tabular}


Cuadro 9. Coediciones más vendidas en 2018

\begin{tabular}{|l|l|l|l|l|c|}
\hline Editoriales & Sub-género & Título & Autoría & Clasificación & Cant. \\
\hline $\begin{array}{l}\text { Editorial de la UNC y } \\
\text { Encuentro Grupo Editor }\end{array}$ & Historia & $\begin{array}{l}\text { Medicina, mito y magia en } \\
\text { Hispanoamérica. El encuentro de dos } \\
\text { mundos: antagonismo y contribución }\end{array}$ & $\begin{array}{l}\text { Carlos Alberto } \\
\text { Cornaglia }\end{array}$ & $\begin{array}{l}\text { Colección } \\
\text { Sociedad. }\end{array}$ & 18 \\
\hline
\end{tabular}

Fuente: elaboración propia a partir de la información relevada Feria 2019 por la LUA

Otro tópico que ha surgido del análisis ha sido el lugar que ocuparon las traducciones en la comercialización en feria. Existen variaciones que muestran diferencias notables (cuyo desarrollo escapa a los objetivos de este artículo) entre sellos universitarios que cuentan en su catálogo con numerosas traducciones, otros que han incursionado muy poco en ello e incluso algunos como EDUNT -según su directora editorial "no somos una editorial que pueda por el momento plantearse traducir" (entrevista propia, 10 de abril de 2019)- que por sus condiciones estructurales, coyunturales y/o por sus finalidades están aún distantes de definir una política editorial en este sentido. Sin embargo, en la circulación del conocimiento las editoriales tienen un papel destacado y en la traducción de libros de Ciencias Sociales y Humanas el inglés es la lengua central que estructura el mercado global (Sapiro, 2018).

Cuadro 10. Traducciones más vendidas en el período 2014-2017

\begin{tabular}{|c|c|c|c|c|c|c|}
\hline Editorial & Sub-género & Título & Autoría & Traducción & Clasificación & Cant. \\
\hline EUDEM & Sociología & Sociología de la familia & Martine Segalen & Susana Murgia & $\begin{array}{l}\text { Otros Libros del } \\
\text { Fondo Editorial }\end{array}$ & 19 \\
\hline $\begin{array}{l}\text { Ed. UNGS - } \\
\text { Clacso }\end{array}$ & Economía & Textos Escogidos. & Karl Polanyi. & $\begin{array}{l}\text { Gabriela } \\
\text { Ventureira, Ana } \\
\text { Gómez }\end{array}$ & $\begin{array}{l}\text { Colección } \\
\text { Lecturas de } \\
\text { Economía Social }\end{array}$ & 19 \\
\hline $\begin{array}{l}\text { UNR } \\
\text { Editora }\end{array}$ & Antropología & $\begin{array}{l}\text { Zonas de frontera: la } \\
\text { antropología frente a la } \\
\text { trampa identitaria }\end{array}$ & Michel Agier & Marcela Gianni & & 13 \\
\hline $\begin{array}{l}\text { UNGS } \\
\text { Ediciones }\end{array}$ & Sociología & $\begin{array}{l}\text { Bibliotecas en llamas. } \\
\text { Cuando las clases populares } \\
\text { cuestionan la sociología y la } \\
\text { política }\end{array}$ & Denis Merklen. & $\begin{array}{l}\text { Heber } \\
\text { Ostroievsky, } \\
\text { Florencia } \\
\text { Dansilio, Ignacio } \\
\text { Dansilio, } \\
\text { Eduardo Rinesi } \\
\end{array}$ & $\begin{array}{l}\text { Colección } \\
\text { Textos } \\
\text { Institucionales: } \\
\text { Cuadernos de la } \\
\text { Lengua }\end{array}$ & 13 \\
\hline EUDEM & Literatura & La Violación de Lucrecia & $\begin{array}{l}\text { William } \\
\text { Shakespeare }\end{array}$ & $\begin{array}{l}\text { Miguel Angel } \\
\text { Montezzanti }\end{array}$ & $\begin{array}{l}\text { Colección } \\
\text { Leciart }\end{array}$ & 11 \\
\hline EUDEBA & Derecho & Teoría pura del derecho & Hans Kelsen & Traducción S/R & $\begin{array}{l}\text { Colección } \\
\text { Derecho }\end{array}$ & 11 \\
\hline $\begin{array}{l}\text { UNM } \\
\text { Editora }\end{array}$ & Economía & $\begin{array}{l}\text { ¿El capitalismo es } \\
\text { insuperable? }\end{array}$ & Cédric Durand & Emilia Ghelfi & $\begin{array}{l}\text { Col. Biblioteca } \\
\text { de Economía }\end{array}$ & 10 \\
\hline
\end{tabular}

Fuente: elaboración propia a partir de la información relevada Feria 2014-2017 por la LUA

La traducción de autoras y autores internacionales a través de la incorporación de obras extranjeras al catálogo, y su presencia en la feria, aunque no haya sido significativa en términos comerciales (Cuadros 10,11,12), posibilitó la consideración de tres cuestiones clave. Primero, las traducciones de literatura y de libros de Ciencias Humanas y Sociales como sostienen Dujovne, Ostroviesky y Sorá (2014) han permitido posicionar la marca y prestigio de los sellos que lideran el volumen de obras traducidas en nuestro país y en el cual la incidencia del francés se basa tanto en los intercambios entre editoriales argentinas y francesas como en políticas de subsidios a la traducción del gobierno francés, lo cual le ha brindado su impronta particular al mercado editorial argentino. Dicha impronta podría pensarse que también impregna los catálogos de las editoriales universitarias y a pesar de la centralidad del inglés en el 
mercado global, el francés predomina en las traducciones más vendidas en el stand de la REUN-CIN. Segundo, varios de los títulos comercializados (Cuadros 10 y 12) corresponden a Sociología y a Cultura, subgéneros que en relación con las coediciones o con los títulos más vendidos por sello no fueron particularmente relevantes. Tercero, algunos sellos -Libros UNA es un claro ejemplo de ello- se han ido configurando y, a su vez, encontrando la visibilidad y reconocimiento de su marca en el área de las traducciones.

Cuadro 11. Traducciones más vendidas en 2018

\begin{tabular}{|l|l|l|l|l|l|c|}
\hline Editorial & Sub-género & Título & Autoría & Traducción & Clasificación & Cant. \\
\hline Libros UNA & Arte & $\begin{array}{l}\text { Aby Warburg y la imagen en } \\
\text { movimiento }\end{array}$ & $\begin{array}{l}\text { Philippe-Alain } \\
\text { Michaud }\end{array}$ & Víctor Goldstein & $\begin{array}{l}\text { Colección } \\
\text { Enfoques }\end{array}$ & 16 \\
\hline
\end{tabular}

Fuente: elaboración propia a partir de la información relevada Feria 2018 por la LUA

Cuadro 12. Traducciones más vendidas en 2019

\begin{tabular}{|l|l|l|l|l|l|c|}
\hline Editorial & Sub-género & Título & Autoría & Traducción & Clasificación & Cant. \\
\hline Libros UNA & Cultura & La mediación cultural & $\begin{array}{l}\text { Bruno Nassim } \\
\text { yrançois } \\
\text { Mairesse }\end{array}$ & $\begin{array}{l}\text { Heber } \\
\text { Ostroviesky }\end{array}$ & $\begin{array}{l}\text { Colección } \\
\text { Enfoques }\end{array}$ & 23 \\
\hline $\begin{array}{l}\text { UNSAMedita y } \\
\text { Fundación CIPAC }\end{array}$ & Psicología & $\begin{array}{l}\text { La fabricación de los hijos. } \\
\text { Un vértigo tecnológico }\end{array}$ & $\begin{array}{l}\text { François } \\
\text { Ansermet }\end{array}$ & Gerardo Losada & $\begin{array}{l}\text { Colección Serie } \\
\text { Tyché }\end{array}$ & 20 \\
\hline Libros UNA & Arte & $\begin{array}{l}\text { Aby Warburg y la imagen en } \\
\text { movimiento }\end{array}$ & $\begin{array}{l}\text { Philippe-Alain } \\
\text { Michaud }\end{array}$ & Víctor Goldstein & $\begin{array}{l}\text { Colección } \\
\text { Enfoques }\end{array}$ & 11 \\
\hline UNDAV Ediciones & Cultura & Redefinir el museo & $\begin{array}{l}\text { André } \\
\text { Desvallées } \\
\text { yrançois } \\
\text { Mairesse. }\end{array}$ & Melina Blostein & $\begin{array}{l}\text { Fuera de } \\
\text { Colección }\end{array}$ & 11 \\
\hline
\end{tabular}

Fuente: elaboración propia a partir de la información relevada Feria 2019 por la LUA

En suma, el análisis realizado permite mostrar específicamente un sector importante para la bibliodiversidad como lo son las editoriales universitarias argentinas, y a partir de allí observar diferenciaciones con la de otros países. En este sentido, el libro científico - producto de investigación original en áreas como Ciencia, Tecnología, Ciencias Sociales, etc.- según Giménez-Toledo, Tejada-Artigas y Mañana-Rodríguez (2018) es protagonista en la producción editorial universitaria en el ámbito iberoamericano, correspondiendo el $85 \%$ de la producción de los sellos españoles y el $86 \%$ de las latinoamericanas. Sin embargo, en relación con otros géneros editados, observan diferencias significativas: mientras los libros de creación literaria constituyen el 44\% de las publicaciones de las editoriales latinoamericanas, no destacan en las españolas, en las cuales representan el 15\%. En tanto que, en estas últimas, la edición de manuales docentes es predominante en el $85 \%$ de las editoriales, solo representa un $38 \%$ de los libros publicados por las latinoamericanas. Ante estos datos concluyen que no todas las universidades comparten las mismas ideas sobre lo que sus editoriales deben potenciar en sus publicaciones.

En Argentina, lo que cada universidad considera editar es una discusión que se redefine constantemente por varios factores: algunos más generales que están en concomitancia a los cambios del mercado editorial -los costos de producción alteran los planes editoriales año a año que muchas veces dependen de los presupuestos universitarios-; de las transformaciones en las prácticas y consumos de los públicos 
lectores; otros están más ligados a procesos institucionales como lo son la coexistencia en más de una universidad de una editorial o línea de publicaciones; y de las decisiones de los directivos y de las directivas editoriales y sus equipos, tanto como a algunas transformaciones que se pueden dar en el marco de las universidades en las que se inscriben. La publicación de libros científicos, aunque prioritaria como en el resto de los países, es solo una de las partes del catálogo de los sellos universitarios.

Las editoriales apuntan a ser más diversas y a convocar no solo al público de universidades sino también a otros públicos más amplios a través de sus colecciones. En esta clave es que se entiende (como muestran los cuadros anteriores) las compras efectivas que se realizaron en el stand colectivo REUN-CIN de libros de Ensayos, Narrativas, Poesía, Literatura Infantil y Juvenil, entre otros, y que para algunas editoriales sean los que más ventas les reportan, tales como las coediciones de Literatura de Ediciones UNL y EDUNER; Rock correntino, pue de Javier "Pelo" Vallejos Amil, publicado por EUDENE; Yonena, yo princesa de Gabriela Mansilla que trata sobre infancias diversas, y La revolución de las mujeres de Luciana Peker, editados por Ediciones UNGS y por EDUVIM respectivamente. Estos dos últimos parecen irse configurando como libros de fondo para estos sellos y durante varios años han sido primeros en ventas en el stand (Mihal, 2019b).

La consideración de la autoría, asimismo, posibilitó visualizar que la comercialización ha estado centrada en libros de autoría individual, de autores académicos, y en menor medida son el resultado de compilaciones o coordinaciones. Pero en cuanto a impacto numérico en la cantidad de ejemplares, resaltan los de Género(s) recién mencionados, cuyas autoras provienen más del mundo periodístico o de la militancia activa. También los de Literatura Infantil y Juvenil de EDUNLA Cooperativa y de EUDEBA, en el primero de los casos por medio de un autor que forma parte del cuerpo académico de la universidad y es autor en otras editoriales comerciales. En el segundo caso, con una autora de gran relevancia en ventas en otras editoriales tanto como en la configuración del campo literario orientado a las infancias en nuestro país.

Por último, se advierte cómo hay editoriales que en el transcurso de los años analizados han vendido títulos constitutivos de una misma colección, como Ediciones UNTDF con la Colección "De eso no se habla" o Libros UNA con la Colección "Enfoques"; o cómo EDUNAM logra adentrarse en las ventas con libros de Antropología, o EDUNT con libros orientados a las cátedras, por citar algunos ejemplos. De este modo, de la mirada sobre las colecciones emerge cuáles son las colecciones o series que funcionan mejor en ventas, dato que las propias editoriales tienen en cuenta en sus prácticas cotidianas y que les posibilita tomar decisiones respecto a sus catálogos.

\section{Consideraciones finales}

Con este trabajo procuré profundizar en cuál es la dinámica de las ventas de las editoriales en un stand colectivo en la Feria Internacional del Libro de Buenos Aires, del 2014 a 2019. Este abordaje cualitativo permitió comprender en esta circulación desde la incidencia de la ubicación en esta feria del stand REUN-CIN, hasta cómo se mueven y posicionan las editoriales en dicho marco. Atender al conjunto de sellos de universidades nacionales y no solo a aquellos que lideran las ventas año a año tuvo la finalidad de ampliar la perspectiva hacia otras editoriales que están inscriptas en la REUN y sobre las que frecuentemente se conoce poco -sea porque su peso en la comercialización es débil en comparación con otros sellos universitarios o porque son de constitución reciente y tienen solo algunos títulos editados, o porque no se han integrado de manera fuerte en el mercado editorial-. 
A través del análisis exploré y puse de relieve algunas tendencias de las editoriales universitarias en este evento en el cual asiste gran afluencia de públicos diversos. Respecto a la consideración de cómo los títulos más elegidos en la comercialización integran las colecciones - y en menor medida las series y secciones- que siguen siendo las grandes articuladoras de estos catálogos, y aún más en las editoriales que lideran en ventas.

Asimismo, el detenimiento sobre la autoría de cada título contribuyó a observar que los libros de autoría individual predominan por sobre los de autoría colectiva como las compilaciones o libros con dirección. Si bien mayoritariamente son libros de autoría académica -entiendo por esta aquella que se rige por normas cuyos sentidos forman parte de un discurso disciplinario, en el cual se configuran y reconfiguran constantemente relaciones institucionales y sociales (Murrell, 2019)-, dada las características de los sellos de las universidades y sus apuestas a generar catálogos bibliodiversos, también se registran autores y autoras provenientes de la escena musical, periodística, literaria, por citar sólo algunos. Sin embargo, son principalmente estas autorías las que han encabezado la comercialización en cantidad de ejemplares de un mismo título. Una de las preguntas que emerge ante esto, es si en otros eventos y puntos de comercialización -stands individuales, otros stands en ferias, librerías universitarias, librerías comerciales- dichos títulos son los que lideran en las ventas de cada editorial.

A partir de las coediciones fue posible relevar algunas de las redes que establecen los sellos universitarios con otras editoriales inscriptas en la REUN-CIN tanto como con editoriales comerciales, independientes, instituciones, entre otras, para el desarrollo de ciertos títulos de sus catálogos. Una línea para proseguir su análisis consiste en la indagación acerca de cómo se seleccionan dichas obras y se establecen los acuerdos de coedición en cada caso en particular. Por otra parte, estas redes se refuerzan a través de la búsqueda de potenciales aliados comerciales en las proximidades de los stands en la feria tanto como en obtener mayor visibilidad en los pabellones en los cuales exponen sellos y librerías académicas.

Las Ciencias Sociales y Humanas inclusive en las traducciones y coediciones son predominantes y varios de sus títulos responden a temas de la agenda pública y académica y no solo editorial. En este sentido, se evidencia cómo la edición universitaria dialoga con los públicos diversos a los que apunta, a través de libros como lo son los de Género(s) y Política y muestra avances en las selecciones de subgéneros específicos como el de Literatura. Una pregunta que subyace respecto a las traducciones es cuántos de los sellos que comercializaron títulos cuentan con ellas en sus catálogos, para observar su internacionalización. Asimismo, se ha visto cómo ciertos subgéneros como Sociología asoman significativamente en las ventas de traducciones exclusivamente. Otro de los interrogantes que se abre es cuál es el porcentaje de cada gran género en el catálogo de los sellos.

Los libros dedicados a cátedras universitarias o temas específicos se configuran también como una parte menos importante en la cantidad de ejemplares, aunque muestran elecciones de diccionarios, manuales y libros que son resultado de investigaciones, o referentes de la vida académica, entre otros. Algunas editoriales más que otras han logrado sostener sus ventas apuntando al perfil de las personas que estudian en las universidades en que los sellos se emplazan.

Por último, la atención en la comercialización de la producción editorial y no en el análisis de la producción en sí misma procuró brindar un panorama extensivo en un espacio y un período concreto, que posibilitó abrir nuevos interrogantes sobre una parte de la edición universitaria argentina. 


\section{Q Referencias bibliográficas}

»Bonacci, Juan M. 2012. Sobre libros, editoriales y sociólogos: La edición de textos en la sociología argentina durante la transición y pos transición democrática (1983-1995). Trabajo presentado en VII Jornadas de Sociología de la Universidad Nacional de La Plata, realizadas en La Plata del 5 al 7 de diciembre de 2012. <http://www.memoria.fahce.unlp.edu.ar/trab_eventos/ev.1733/ev.1733. pdf.> [Consulta: 29 febrero 2021].

"Chartier, Roger. 2007. Conferencia inaugural: La universidad como contexto para la edición de libros. Pasado, presente y futuro. En Polo Pujadas, Magda, coord. Innovación y retos de la edición universitaria. Madrid: UNE. p. 13-28.

»Chartier, Roger. 2014. El compromiso sigue siendo con las prácticas de la lectura. La edición universitaria y sus desafíos. Entrevista realizada por Carlos Gazzera y Darío Stukalsky, 28 de septiembre de 2014. <http://reun-lua.blogspot.com/2014/og/la-edicionuniversitaria-y-sus-desafios.html> [Consulta: 29 febrero 2021].

»Costa, Flavia y Leandro de Sagastizábal. 2016. Las editoriales universitarias: los caminos de la profesionalización. En Anuario del Centro de Estudios Económicos de la Empresa y el Desarrollo. Año 8, no. 8, 157-182. <ojs.econ.uba.ar/ojs/ index.php/CEEED/issue/download/150/Anuario\%202016> [Consulta: 29 febrero 2021].

»Dujovne, Alejandro. 2019. Ampliación y límites estructurales de la edición universitaria argentina. Un análisis de la producción y distribución editorial entre 2014 y 2019. En Revista Telar. No. 23, 91-118. <http://revistatelar.ct.unt.edu.ar/ index.php/revistatelar/article/view/448> [Consulta: 29 febrero 2021].

"Dujovne, Alejandro, Heber Ostroviesky y Gustavo Sorá. 2014. La traducción de autores franceses de ciencias sociales y humanidades en la Argentina. Estado y perspectivas actuales de una presencia invariante. En Bibliodiversity - Journal of publishing in globalization. No. 3, 20-30.

» Giménez-Toledo, Elea; Carlos Tejada-Artigas y Jorge Mañana-Rodríguez. 2018. Las editoriales universitarias iberoamericanas: una aproximación a su perfil y a sus procesos de selección de originales. En Revista Española de Documentación Científica. Vol. 41, no. 2, e205. <https://doi.org/10.3989/redc.2018.2.1459>

» Mihal, Ivana. 2019a. La edición universitaria argentina a la luz de la Feria del Libro de Guadalajara: acerca de la internacionalización y digitalización. En Cuadernos del Centro de Estudios en Diseño y Comunicación. Año, 21, no. 85, 49-69. <https://doi.org/10.18682/cdc.vi85.3751>

" Mihal, Ivana. 2019b. Políticas editoriales universitarias y apuestas a catálogos con perspectiva de género(s). En Revista Telar. No. 23, 117-136. <http://revistatelar.ct.unt.edu.ar/index.php/revistatelar/article/view/449> [Consulta: 29 febrero 2021].

" Mihal, Ivana y Laura R. García. 2020. La edición de la literatura infantil y juvenil argentina a través de las editoriales universitarias: EDUVIM y Ediciones UNL. En Moderna språk. Vol. 114, no. 1, 139-159. <http://ojs.ub.gu.se/ojs/index.php/ modernasprak/article/view/4710> [Consulta: 29 febrero 2021].

" Murrell, Mary. 2019. What is an (Academic) author, 8 de marzo. <http://www. marymurrell.net/what-is-an-academic-author/> [Consulta: 29 febrero 2021]. 
》 REUN-CIN. 2019. Encuesta sobre Edición Universitaria Pública Argentina (2019), dirigida por A. Dujovne. Observatorio de la Edición Universitaria Pública Argentina, Informe provisorio, abril.

» Sapiro, Gisèle. 2018. ¿Cuáles factores determinan la circulación internacional de los libros académicos? El ejemplo de traducciones entre inglés y francés en la era de la globalización. En Contraportada. No. 3, 6-39. <https://es.calameo. com/books/o0415073701c8d44b6b3d> [Consulta: 29 febrero 2021].

"Soares Rodrigues, Lidiane y José de Souza Muniz Jr. 2018. Presentación Dossier Libros, editoriales y ciencias sociales. En Prisma. Revista de historia intelectual. Vol. 22, no. 2, 153-156. <https://historiaintelectual.com.ar/OJS/index.php/Prismas/article/view/Soares_deSouza_prismas22> [Consulta: 29 febrero 2021].

"Sorá, Gustavo. 2002. Frankfurt y otras aduanas culturales entre Argentina y Brasil. Una aproximación etnográfica al mundo editorial. En Cuadernos de Antropología Social. No. 15, 125-143. <https://doi.org/10.34096/cas.i15.4621>

"Sorá, Gustavo. 2016. Primitivas y futuristas: las ferias de libros bajo el prisma de la sociología. En Revista Bepé. Año 10, no. 18, 19-23. <http://www.conabip. gob.ar/sites/default/files/REVISTA\%20BP\%2018\%20_MAYO_2016_WEB.pdf> [Consulta: 29 febrero 2021].

» Szpilbarg, Daniela. 2017. Políticas editoriales, autogestión y asociativismo en la edición argentina contemporánea (2012-2017). Trabajo presentado en Jornadas Políticas Editoriales de la Biblioteca Nacional, realizadas en Buenos Aires del 1 al 3 de noviembre de 2017.

"Thompson, John. 2005. Books in the Digital Age. The Transformation of Academic and Higher Education Publishing in Britain and the United States. Cambridge: Polity Press.

»Weinberg, Gregorio. [1972] 2020. La industria editorial y las editoriales universitarias. En Weinberg, Pedro Daniel, ed. Escritos sobre el libro y la edición en América Latina. Buenos Aires: CLACSO; UNIPE: Editorial Universitaria, p. 113-130. $<$ http://biblioteca.clacso.edu.ar/clacso/se/20201111053129/Escritos-sobre-libro.pdf> [Consulta: 29 febrero 2021]. 